Article

\title{
Energy-Saving Strategies and their Energy Analysis and Exergy Analysis for In Situ Thermal Remediation System of Polluted-Soil
}

\author{
Tian-Tian Li ${ }^{1}$, Yun-Ze Li ${ }^{1,2,3, * \mathbb{C}}$, Zhuang-Zhuang Zhai ${ }^{4}$, En-Hui $\mathrm{Li}^{1}{ }^{\text {and }}$ Tong $\mathrm{Li}^{5}$ \\ 1 School of Aeronautic Science and Engineering, Beihang University, Beijing 100191, China; \\ litiantian@buaa.edu.cn (T.-T.L.); lienhui@buaa.edu.cn (E.-H.L.) \\ 2 Institute of Engineering Thermophysics, North China University of Water Resources and Electric Power, \\ Henan 450045, China \\ 3 Advanced Research Center of Thermal and New Energy Technologies, Xingtai Polytechnic College, \\ Hebei 054035, China \\ 4 School of Automation Science and Electrical Engineering, Beihang University, Beijing 100191, China; \\ zhaizz@buaa.edu.cn \\ 5 Chengyi Academy of PKUHS, Peking University, Beijing 100080, China; litong@i.pkuschool.edu.cn \\ * Correspondence: liyunze@buaa.edu.cn; Tel.: +86-10-82338778; Fax: +86-10-82315350
}

Received: 8 October 2019; Accepted: 20 October 2019; Published: 22 October 2019

\begin{abstract}
The environmental safety of soil has become a severe problem in China with the boost of industrialization. Polluted-soil thermal remediation is a kind of suitable remediation technology for large-scale heavily contaminated industrial soil, with the advantages of being usable in off-grid areas and with a high fuel to energy conversion rate. Research on energy-saving strategies is beneficial for resource utilization. Focused on energy saving and efficiency promotion of polluted-soil in situ thermal remediation system, this paper presents three energy-saving strategies: Variable-condition mode (VCM), heat-returning mode (HRM) and air-preheating mode (APM). The energy analysis based on the first law of thermodynamics and exergy analysis based on the second law of thermodynamics are completed. By comparing the results, the most effective part of the energy-saving strategy for variable-condition mode is that high savings in the amount of natural gas (NG) used can be achieved, from 0.1124 to $0.0299 \mathrm{~kg} \cdot \mathrm{s}^{-1}$ in the first stage. Energy-saving strategies for heat-returning mode and air-preheating mode have higher utilization ratios than the basic method (BM) for the reason they make full use of waste heat. As a whole, a combination of energy-saving strategies can improve the fuel savings and energy efficiency at the same time.
\end{abstract}

Keywords: contaminated soil; polluted soil; thermal desorption; thermal remediation; energy analysis and exergy analysis; energy saving

\section{Introduction}

Soil is the basic environmental element constituting the ecosystem, and the important material basis of human survival and development. The environmental safety of soil has become a severe problem in China with the boost of industrialization and urbanization. It was calculated that the amount of contaminated soil reached about 150 million mu up to 2012 [1]. Recent estimates indicate that 500,000 sites in Europe require cleanup, while nearly 3.5 million sites are potentially polluted [2]. Including heavy metals, soil contamination caused by so many contaminants is an urgent problem. It can be seen from the bulletin on Chinese domestic environmental conditions for the year 2000 that the heavy metals in 36,000 hectares of soil were out of limits in the surveyed 0.3 million hectares of soil and the over standard rate reached $12.1 \%$ of the total [3]. The prevention of contaminated soil 
is not only needed to control the sources such as heavy metals, but also enhance the remediation of contaminated soil [4]. In the last 30 years since 2013, more than 80,000 sites have been cleaned up in the European countries where data on remediation are available [5].

In situ thermal remediation is a kind of suitable remediation technology for heavily contaminated soil $[6,7]$. Thermal desorption removes pollutants from soil and other materials by using heat to change the chemicals into gases and speed up the cleanup of many pollutants from the ground [8-10]. All the soil contamination remediation mechanisms have their advantages and limitations. Moreover, they are contaminant specific and heavily dependent on the subsurface environmental conditions of the site [11]. In situ thermal remediation remedies contaminated soil on the contaminated site without excavation. Compared with ex situ thermal desorption (ESTD), it has the advantages of low investment and little impact on the surrounding environment, so it is a hotspot of soil remediation research [12-14]. In situ thermal remediation is a soil remediation process in which heat and vacuum are applied simultaneously to subsurface soils [15]. Volatile and semi-volatile organics are removed from contaminated soil in thermal desorbers at 100 to $300^{\circ} \mathrm{C}$ for low temperature thermal desorption, or at 300 to $550^{\circ} \mathrm{C}$ for high-temperature thermal desorption [16]. In the past decade, it has been applied at a number of sites and it has been used in various modes including surface heating with blankets, subsurface heating with an array of vertical heater/vacuum wells, and ex situ blankets [15]. During the remediation process, gases at high temperature $\left(700-800{ }^{\circ} \mathrm{C}\right)$, coming from the combustion chamber, circulate within the heating elements, resulting in the heating of the soil and the evaporation of volatile pollutants (boiling point $<550^{\circ} \mathrm{C}$ ) contained in the soil [17]. Laboratory treatability studies and field project experience have confirmed that the combination of high temperature and long-time results in extremely high overall removal efficiency, even for high boiling point contaminants. Both thermal wells and thermal blankets have been demonstrated to be highly effective in removing a wide variety of low and high boiling point hydrocarbons, PCBs, pesticides, and chlorinated solvents from soils [15]. Shallow soil contamination (less than three feet deep) may be treated by thermal blankets or horizontal wells $[11,18]$. For soil contamination at depths greater than 3 feet, heating with surface blankets is ineffective and thermal wells are needed to attain high temperatures in the soil [15].

Figure 1 presents a general description of a traditional in situ thermal remediation system, that is a polluted-soil thermal remediation system including burner, pipe, well and soil. As Figure 1a shows, natural gas (NG) and air enter the burner through different inlets and an air-NG mixture is delivered to the burner, in which chemical energy of natural gas (NG) is converted to thermal energy in the exhaust gas by burning. The high temperature exhaust gas produced by the burner flows through the pipe into the heating well inserted vertically in the soil. The well is the heat transfer component of the whole system, in which the high temperature exhaust gas flows transferring heat to the soil to raise the soil temperature through the walls of the well. The volatile pollutants contained in the soil will then evaporate. As shown in Figure 1b, the gas flows directly in the system and is eventually discharged into the environment without recovery or recycling. In such a flow, the energy in the flowing gas is used only once to heat the soil. From the point of view of energy utilization, this is undoubtedly a huge waste.

At present, there are many studies on soil contamination, mainly about remediation methods, such as thermal desorption, chemical oxidation, phytoremediation etc. [19-25], assessment of contaminated soil [26], the process of soil contamination [27], areas for contaminated soil remediation, etc. [28]. However, few studies have focused on the energy saving and efficiency promotion of thermal desorption using natural gas (NG). Thus, it is very significant to analyze the energy loss and energy utilization ratio of the polluted-soil thermal remediation system. The 2008 gas flaring estimate of 139 billion cubic meters represents $21 \%$ of the natural gas consumption of the USA with a potential retail market value of $\$ 68$ billion and the 2008 flaring added more than 278 million metric tons of carbon dioxide equivalents $\left(\mathrm{CO}_{2} \mathrm{e}\right)$ into the atmosphere. That is to say, improved utilization of the gas is key to reducing global carbon emissions to the atmosphere [29]. 


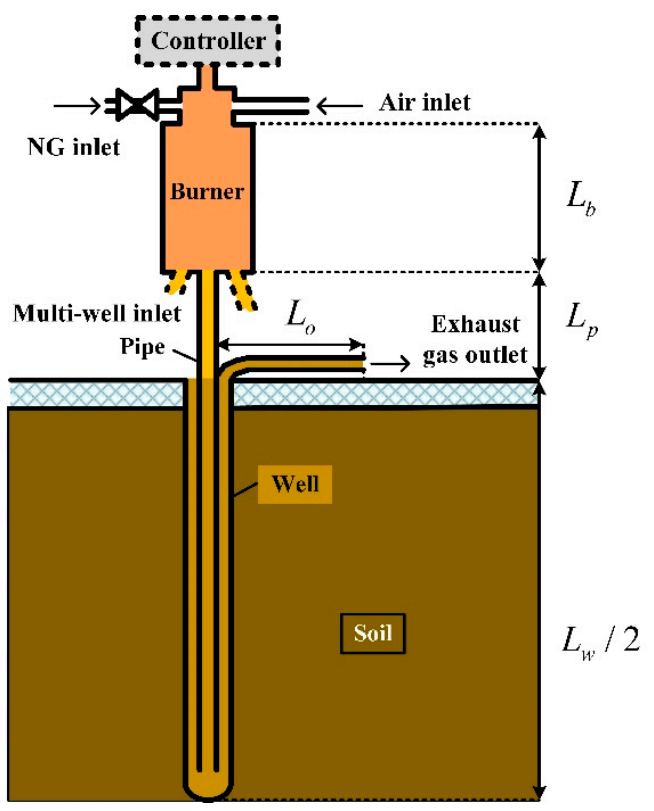

(a)

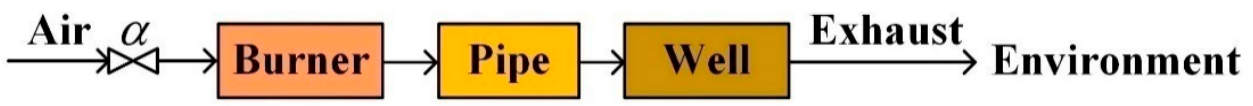

(b)

Figure 1. System diagram of polluted-soil thermal remediation system: (a) Structure diagram of polluted-soil thermal remediation system including burner, pipe, well and soil; (b) flowchart of air distribution in polluted-soil thermal remediation system.

Energy plays an important role in the history of human development [30]. In recent decades economic growth and increased human wellbeing around the globe have come at the cost of fast growing natural resource use (including materials and energy) and carbon emissions, leading to converging pressures of declining resource security, rising and increasingly volatile natural resource prices, and climate change [31]. Emissions of carbon dioxide from the combustion of fossil fuels, which may contribute to long-term climate change [32]. In recent decades, China has encountered serious environmental problem [33]. Some heavy industries and manufacturing enterprises are still characterized by extensive growth, facing enormous environmental challenges due to global climate change, rapid exhaustion of various non-renewable resources, and must improve their energy-save and emission-abate technology to favor the sustainable development [34-36]. Policies should aim to increase the efficiency of energy use [37].

In the energy system, energy analysis based on the first law of thermodynamics and exergy analysis based on the second law of thermodynamics are commonly used. The energy analysis is focused on the quantity of energy and the exergy analysis is focused on the quality of energy. Numerous studies have used these methods, such as the novel combined cooling, heating, and power (CCHP) system [38,39], ground source heat pumps [40], and exhaust waste heat recovery systems [41] and so on.

In the traditional polluted-soil thermal remediation system, the constant high temperature of exhaust is used to heat the soil with changing temperature and the exhaust is discharged directly into the atmosphere, which is disadvantageous for saving energy. Therefore, this paper is aimed at improving the existing problems in the traditional system, and so three energy-saving strategies were researched.

This paper proposes three energy-saving strategies of polluted-soil thermal remediation system-variable-condition mode (VCM), heat-returning mode and air-preheating mode-and their thermal performance and efficiency are discussed by energy analysis and exergy analysis. 
The mathematic models of a polluted-soil thermal remediation system including burner, pipe, well and soil for energy and exergy analysis are built based on thermodynamics, heat transfer and fluid mechanics. Keeping the energy (exergy) at the inlet to the system constant, and various energy (exergy) losses and energy (exergy) utilization ratios at different stages are calculated. The results are graphically formed to compare the energy-saving strategies with the basic method (BM) and to find where the specific embodiment of energy savings is.

\section{Idea of Energy-Saving Strategies of Polluted-Soil Thermal Remediation System}

The three energy-saving strategies are presented to improve on traditional systems as shown in Figure 1, and the environment is the same in the research except for the system. The area of soil researched in the paper is 3 meters long, 3 meters wide and 6 meters deep. The following Sections 2.1-2.3 introduce the three energy-saving strategies, respectively.

\subsection{Description of Energy-Saving Strategy for Variable-Condition Mode}

Energy-saving strategy for variable-condition mode (VCM) involves different exhaust gas temperatures used at different stages. The process of polluted-soil thermal remediation is divided into three stages lasting for 15, 20 and 10 days, respectively, in the study. In the first stage, the soil temperature rises from the initial temperature to the boiling point of water, and the soil moisture content is the initial moisture content. The second stage is the evaporation stage of water in the soil, and the soil keeps the temperature of boiling point of water unchanged. The third stage is to heat dry soil without water to increase the soil temperature to the final temperature. Therefore, the soil temperature is different as well as the soil heating requirements in the three stages, but in the basic method (BM) in use, the exhaust gas temperature at each stage of heating the soil is constant, that is, as shown in Figure 2, the constant high temperature of exhaust used to heat the soil with changing temperature, which is disadvantageous for saving energy. To solve the problem, variable-condition mode (VCM) is necessary, that is, different exhaust gas temperatures are used at different stages. In modeling and analysis, the most direct reflection is that the temperature inside the burner to the temperature outside the heating well are all different at three stages. The contrastive temperature configurations of variable-condition mode (VCM) and the basis method (BM) are presented in Table 1. In the variable-condition mode (VCM), the airflow circulation in polluted-soil thermal remediation system is the same as that in the basis method (BM), as shown in Figure $1 \mathrm{~b}$.

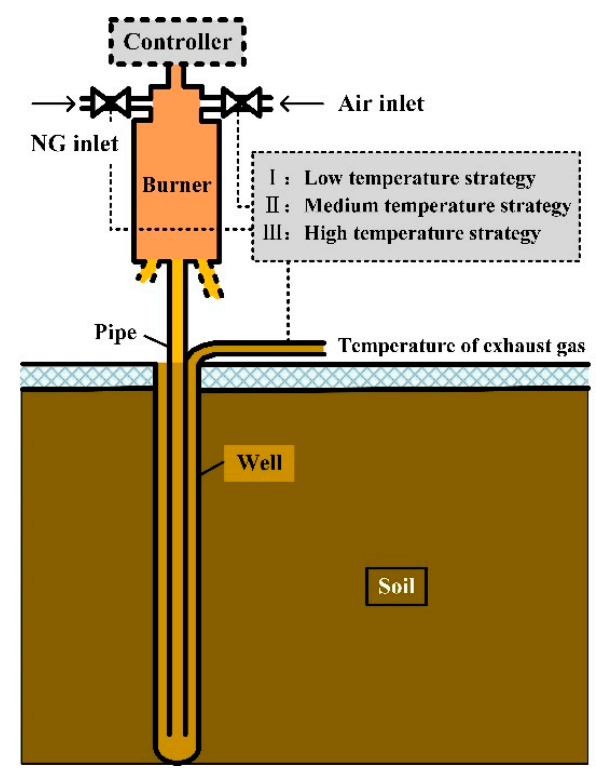

Figure 2. Structure diagram of polluted-soil thermal remediation system using the energy-saving strategy for variable-condition mode (VCM). 
Table 1. Temperature configurations of VCM (variable-condition mode) and BM (basis method).

\begin{tabular}{|c|c|c|c|c|c|c|c|}
\hline Strategy & Stage & $t_{b}\left({ }^{\circ} \mathrm{C}\right)$ & $t_{b, \text { out }}\left({ }^{\circ} \mathrm{C}\right)$ & $t_{w, \text { in }}\left({ }^{\circ} \mathrm{C}\right)$ & $t_{\text {wout }}\left({ }^{\circ} \mathrm{C}\right)$ & $t_{s}\left({ }^{\circ} \mathrm{C}\right)$ & $t_{s, e}\left({ }^{\circ} \mathrm{C}\right)$ \\
\hline \multirow{3}{*}{$\mathrm{BM}$} & I & 950 & 700 & 600 & 450 & 50 & 30 \\
\hline & II & 950 & 700 & 600 & 450 & 100 & 80 \\
\hline & III & 950 & 700 & 600 & 450 & 250 & 200 \\
\hline \multirow{3}{*}{ VCM } & I & 750 & 500 & 450 & 200 & 50 & 30 \\
\hline & II & 800 & 550 & 500 & 300 & 100 & 80 \\
\hline & III & 1050 & 800 & 750 & 600 & 250 & 200 \\
\hline
\end{tabular}

Based on data from engineering practice and a preliminary estimate of the combustion process, the temperature of soil and the temperature in burner in different stage are set in Table 1 . The outlet gas temperature of the heating well $t_{w, o u t}$ is $450{ }^{\circ} \mathrm{C}$ in $\mathrm{BM}$, which is also a temperature often used in engineering practice. In VCM $t_{w, \text { out }}$ is the main way to achieve variable conditions to save energy, and it is set by the authors for the case.

\subsection{Description of Energy-Saving Strategy for Heat-Returning Mode}

The energy-saving strategy for heat-returning mode is returning the heat contained in the exhaust to the polluted-soil thermal remediation system again. In the basic method (BM), the exhaust containing a considerable amount of heat is discharged directly into the atmosphere and that is a great waste. To solve the problem, heat-returning mode is necessary, that is, the exhaust from the outlet of the heating well directly discharged to the environment is returned to the burner as the air in a certain proportion, and three schemes are made according to the different proportion of return gas. The rate of return gas is the rate of heat return $\beta$. The return air enters the burner from air inlet 2, and the amount of air required for combustion to remove this part is the amount of normal air required from air inlet. The airflow circulation of energy-saving strategy for heat-returning mode in polluted-soil thermal remediation system is different from that in the basis method (BM), as shown in Figure 3b.

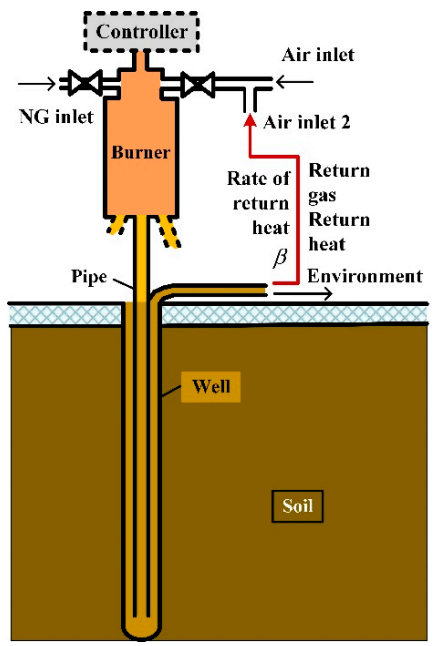

(a)

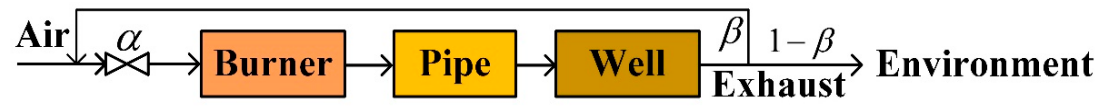

(b)

Figure 3. System diagram of polluted-soil thermal remediation system using the energy-saving strategy for heat-returning mode: (a) Structure diagram of polluted-soil thermal remediation system using the energy-saving strategy for heat-returning mode; (b) flowchart of air distribution in polluted-soil thermal remediation system using the energy-saving strategy for heat-returning mode. 


\subsection{Description of Energy-Saving Strategy for Air-Preheating Mode}

The energy-saving strategy for air-preheating mode is to use the residual heat of the system to -preheat the air entering the burner for combustion. In the basic method (BM), heat from high-temperature parts directly exposed to the environment in the system is wasted and the residual heat can be used up. To solve the problem, preheaters for air-preheating mode are set. As shown in Figure 4, the air to be introduced into the burner is divided into three parts: The first part passes through preheater 1 between the burner and the inlet of heating well, the second part passes through preheater 2 at the outlet pipe of the heating well, and the third part enters the burner directly. Three schemes are designed according to different preheating ratio to different preheaters. The preheating ratio of air through preheater 1 is $\alpha_{1}$, preheating ratio of air through preheater 2 is $\alpha_{2}$ and the ratio of air that does not pass through the preheater directly into the burner is $\alpha_{3}$. The airflow circulation of energy-saving strategy for air-preheating mode in polluted-soil thermal remediation system is different from that in the basis method (BM), as shown in Figure $4 b$.

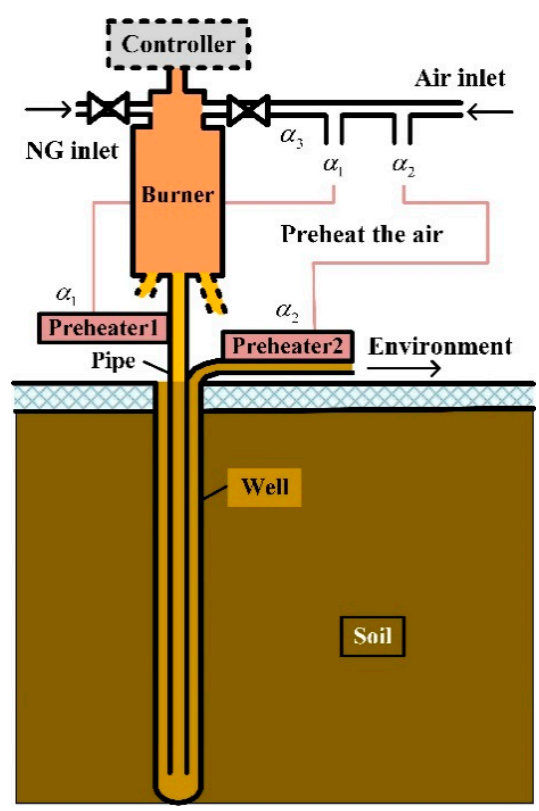

(a)

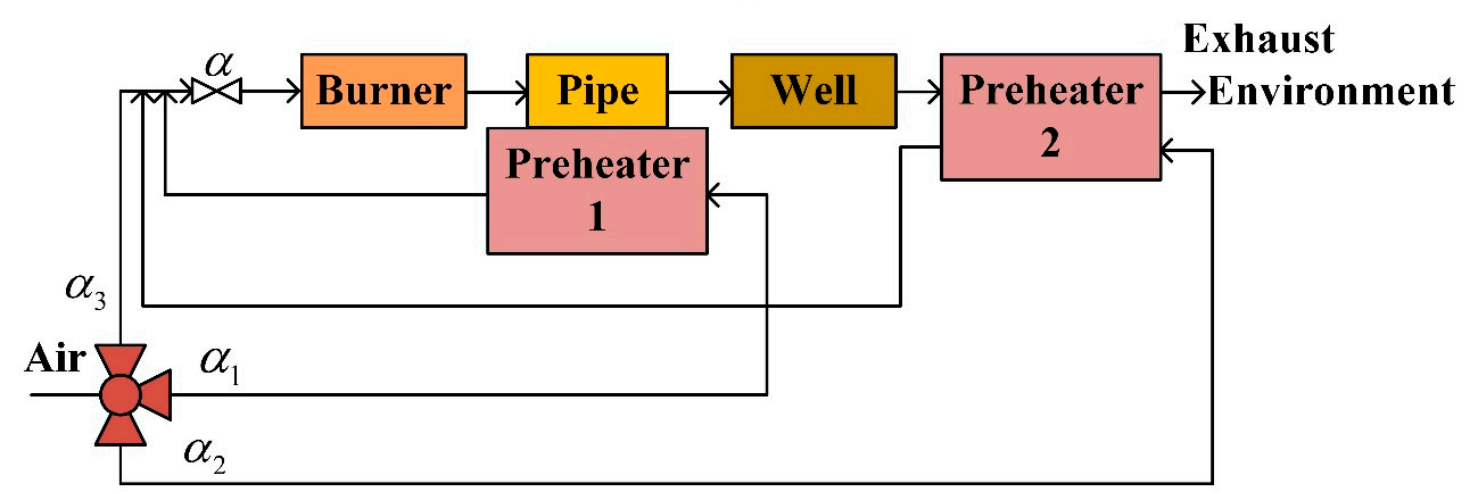

(b)

Figure 4. System diagram of polluted-soil thermal remediation system using the energy-saving strategy for air-preheating mode: (a) Structure diagram of polluted-soil thermal remediation system using the energy-saving strategy for air-preheating mode; (b) flowchart of air distribution in polluted-soil thermal remediation system using the energy-saving strategy for air-preheating mode. 


\section{Mathematic Models and Parameters Calculation Process}

Mathematical models of the polluted-soil thermal remediation system established in this section are used to support the thermal performance analysis of energy-saving strategies. The thermal performance analysis includes an energy analysis based on the first law of thermodynamics and an exergy analysis based on the second law of thermodynamics, so the models are divided into two parts: Section 3.2 presents the energy analysis model and Section 3.3 the exergy analysis model. Energy utilization ratio and exergy utilization ratio, as the key parameters to evaluate the energy-saving strategies, are calculated at the end of the models in Sections 3.2.5 and 3.3.5. Before the specific model, the balance equation is indispensable. The following assumptions are made in the energy and exergy analysis:

(a) The soil is homogeneous and values of physical parameters of the soil remain unchanged in the heat transfer process at the same stage;

(b) The flow of fluid in porous media is called seepage, and the influence of seepage in soil, that is, water migration, was ignored;

(c) The influence of surface temperature fluctuation and depth of buried pipe on soil temperature was ignored, and the soil temperature was considered uniform in the initial stage.

The basic mathematical models in the energy-saving strategies are the same as the basic method (BM), except that the energy and exergy of the air entering the burner are different. In the calculation, paying attention to these parameters is the crucial key of the research. The process of parameters calculation is in the Section 3.4. The value of physical parameters used in the models is shown in Table A1.

\subsection{Balance Models}

The balance models are based on energy loss and exergy loss of each component in the process of energy flow and exergy flow. Figure 5 shows the energy loss of each component of the polluted-soil thermal remediation system. At the beginning of the energy flow throughout the system, the natural gas (NG) and air carry energy through their respective pipes into the burner. When the gas flows through the pipeline, there are throttling and friction process in the flow, which cause an energy loss. Throttling is a local flow loss, while friction is a path loss of flow. In reality, as long as there is flow in the pipeline, there will be flow loss, and as long as there is a pipe with fluid exposed to the environment, there will be heat leakage loss.

In the burner, incomplete combustion caused by inadequate mixes of fuel and air or the low temperature in the combustor cause energy losses. There are also heat leakage, air leakage and flow loss in the burner. After the energy loss is removed, the remaining energy flows out of the burner and through the pipe into the heating well. There are heat leakage and flow loss in the pipe. Local flow loss exists in the heating well because of the bent pipe. Part of the energy flowing to the heating well is transferred to the soil, heating it. The remaining energy is discharged directly to the environment by the outlet of the heating well through high-temperature exhaust gas, resulting in the maximal energy loss of the whole system. In addition to heating up the soil, the energy in the soil will also lose heat to the surrounding non-heating soil zone and to the air through the surface insulation layer.

Figure 6 shows the exergy loss of each component of the polluted-soil thermal remediation system. Energy loss is accompanied by exergy loss, so all of the energy loss described above has the consequent loss of exergy, including incomplete combustion, heat leakage, flow leakage and so on. Besides, Irreversible combustion, heat transfer, non-isothermal heat release and non-isothermal heat absorption also cause the exergy loss. Consequently, the energy and exergy balance of each component are modeled as shown in Sections 3.1.1 and 3.1.2, respectively. 


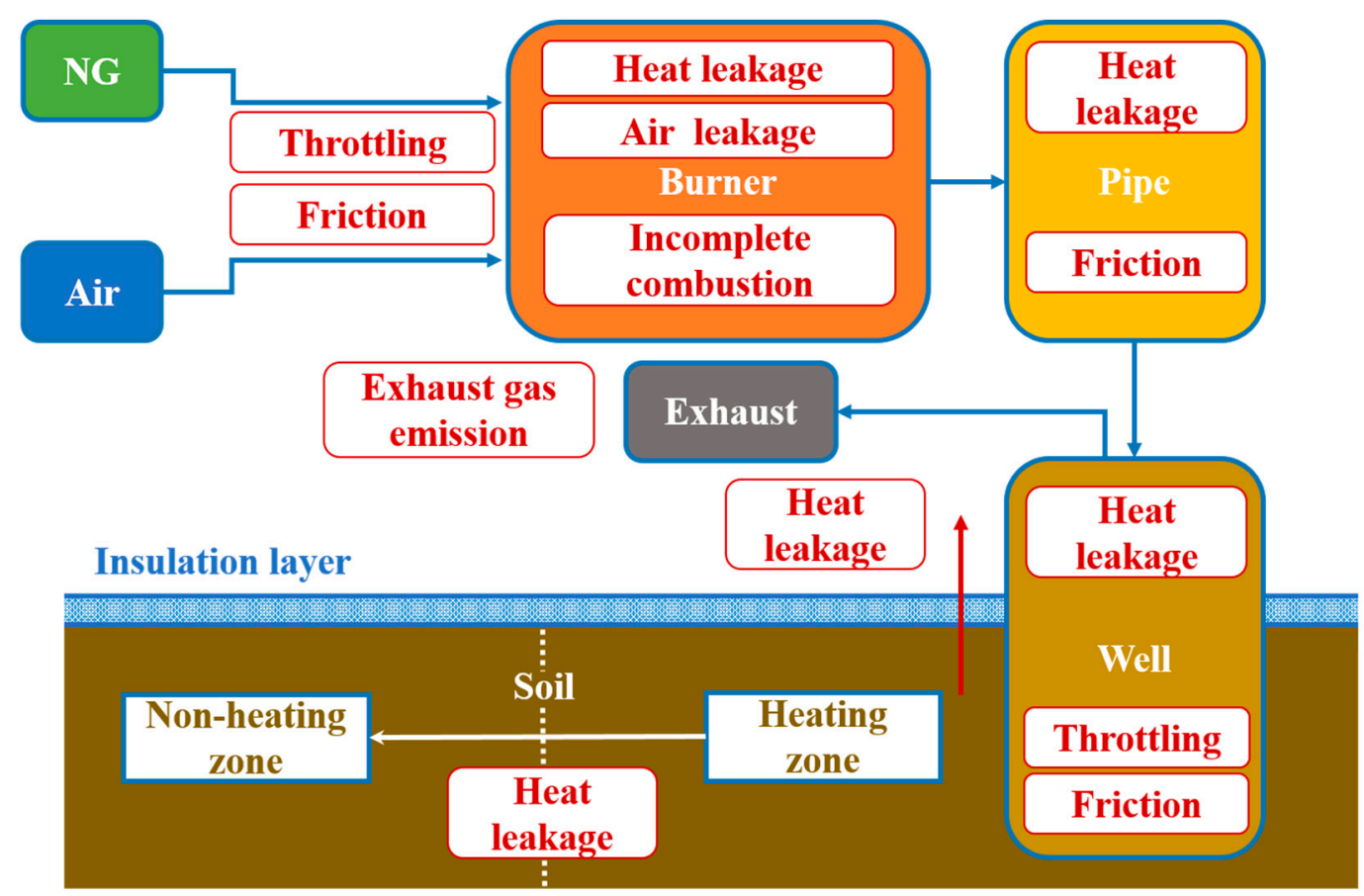

Figure 5. The locations of energy loss of components of polluted-soil thermal remediation system.

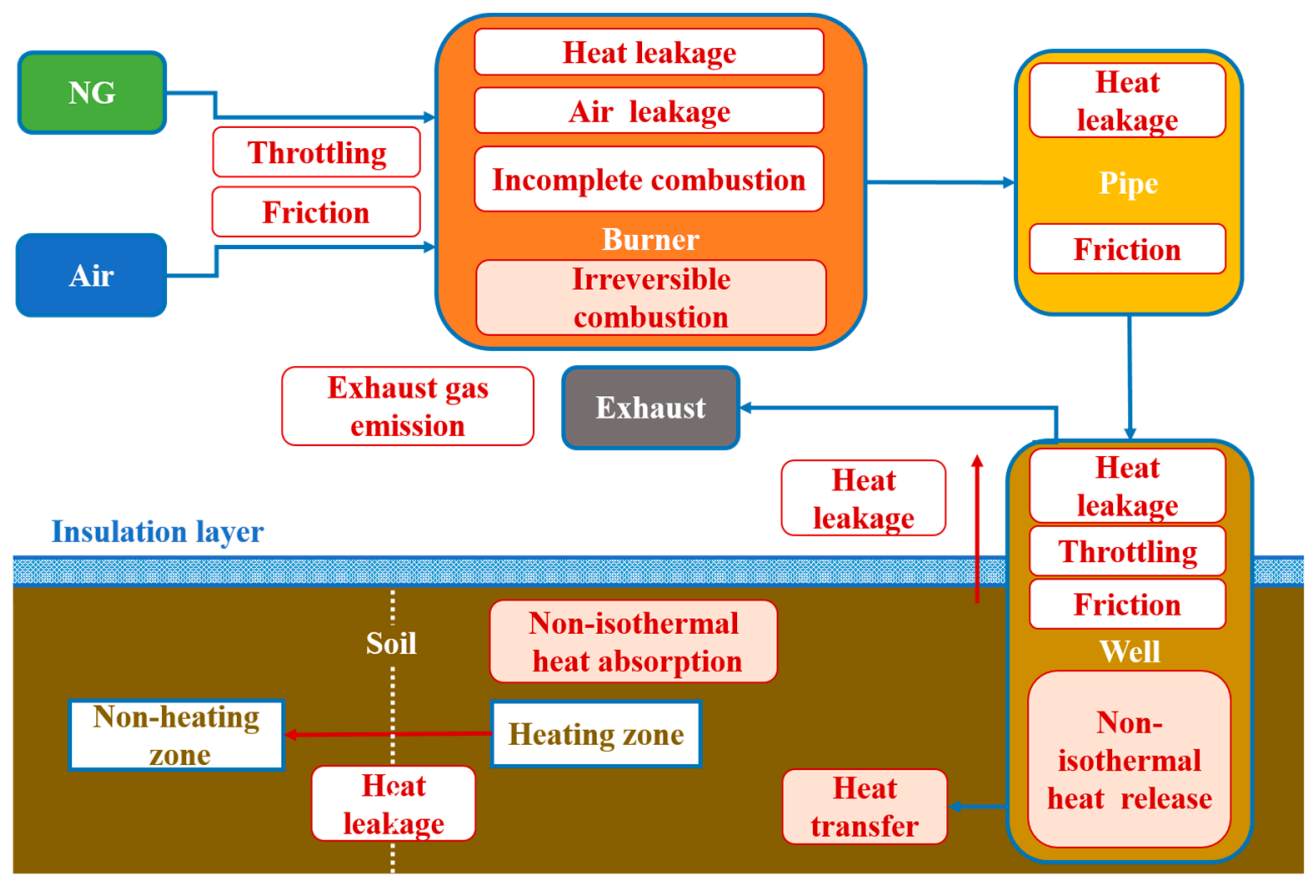

Figure 6. The locations of exergy loss of components of polluted-soil thermal remediation system.

\subsubsection{Energy Balance Models}

Based on the balance of energy principle and energy loss of each component described in Figure 5, the energy balance equation is established as follows. Equations (1)-(4) are the energy balance models of the burner, pipe, well and soil separately:

$$
\begin{gathered}
Q_{a r, n e t}+Q_{a i r}=Q_{b, t o, p}+Q_{b, i n c}+Q_{b, l}+Q_{b, f} \\
Q_{p, i n}=Q_{b, t o, p}=Q_{p, t o, w}+Q_{p, l}+Q_{p, f}
\end{gathered}
$$




$$
\begin{aligned}
Q_{w, \text { in }}=Q_{p, t o, w} & =Q_{w, t o, s}+Q_{w, o u t}+Q_{w, l}+Q_{w, f} \\
Q_{s, \text { in }} & =Q_{w, t o, s}=Q_{s, a}+Q_{s, l}
\end{aligned}
$$

\subsubsection{Exergy Balance Models}

The exergy balance models is similar to the energy balance model, based on the balance of exergy principle and exergy loss of each component described in Figure 6. Equations (5)-(8) are the exergy balance models of the burner, pipe, well and soil, respectively:

$$
\begin{gathered}
E_{r}+E_{a i r}=E_{b, t o, p}+E_{b, i r r}+E_{b, i n c}+E_{b, l}+E_{b, f} \\
E_{p, i n}=E_{b, t o, p}=E_{p, t o, w}+E_{p, l}+E_{p, f} \\
E_{w, \text { in }}=E_{p, t o, w}=E_{w, t o, s}+E_{x, Q}+E_{x, Q_{1}}+E_{w, o u t}+E_{w, l}+E_{w, f} \\
E_{s, i n}=E_{w, t o, s}=E_{s, a}+E_{x, Q_{2}}+E_{s, l}
\end{gathered}
$$

\subsection{Energy Analysis Model}

One kilogram of natural gas (NG) is the total energy source of the system in the research and the study about the energy flow and the energy loss is started with the energy of one kilogram of natural gas (NG). The mass flow rates used in modeling is calculated in Appendix B (a). The convective heat transfer coefficient used in heat leakage modeling is calculated in Appendix B (b). The Reynolds number used in coefficient of path energy loss modeling is calculated in Appendix B (b) as well. The length of each component used in path energy loss modeling is shown in Figure 1 and the value of them is presented in Table A1. The specific energy analysis models of four components are as follows.

\subsubsection{Burner}

(a) $Q_{a r, n e t}$ is the lower calorific value of natural gas (NG), according to the value of the Utility Boiler Manual [42]:

$$
Q_{a r, n e t}=50200 k J
$$

(b) $Q_{a i r}$ is the energy of air and the value is approximately zero:

$$
Q_{\text {air }}=0
$$

(c) Energy loss of incomplete combustion is the product of incomplete combustion coefficient $\varepsilon$ and the lower calorific value of natural gas (NG) $Q_{a r, n e t}$. In the calculation, the value of incomplete combustion coefficient $\varepsilon$ is 0.3 :

$$
Q_{b, i n c}=\varepsilon Q_{a r, n e t}
$$

(d) The calculation of energy loss of heat leakage of burner is abstracted as a mathematical model of the heat transfer process of a cylinder tube with gas flowing in air, so are the energy loss of heat leakage of pipe and the extended part of well, as shown in Figure 5. The calculation of heat leakage energy is based on Fourier's Law and Newton's Law of Cooling of heat transfer theory:

$$
\begin{aligned}
Q_{b, l}= & \frac{2 \pi\left(t_{f, b}-t_{0}\right) L_{b}}{\frac{2}{h_{b, 1} d_{b, 1}}+\frac{1}{\lambda_{b}} \ln \frac{d_{b, 2}}{d_{b, 1}}+\frac{2}{h_{b, 2} d_{b, 2}}} \times \frac{1}{G_{N G}} \times 10^{-3} \\
Q_{p, l}= & \frac{2 \pi\left(t_{f, p}-t_{0}\right) L_{p}}{\frac{2}{h_{p, 1} d_{p, 1}}+\frac{1}{\lambda_{p}} \ln \frac{d_{p, 2}}{d_{p, 1}}+\frac{2}{h_{p, 2} d_{p, 2}}} \times \frac{1}{G_{N G}} \times 10^{-3}
\end{aligned}
$$




$$
Q_{w, l}=\frac{2 \pi\left(t_{f, w}-t_{0}\right) L_{o}}{\frac{2}{h_{w, 1} d_{w, 1}}+\frac{1}{\lambda_{w}} \ln \frac{d_{w, 2}}{d_{w, 1}}+\frac{2}{h_{w, 2} d_{w, 2}}} \times \frac{1}{G_{N G}} \times 10^{-3}
$$

The influence of air leaks is ignored. The convective heat transfer coefficient is different when there's wind and there's no wind. So the calculation of the convective heat transfer coefficient outside the tube is divided into forced convection and natural convection.

(e) Energy loss of flow $Q_{b, f}$ concludes path energy loss and local energy loss, the calculation is based on the algorithm in fluid mechanics:

$$
Q_{b, f}=g\left(\varsigma_{b} \frac{L_{b}}{d_{b, 1}} \frac{u_{b}^{2}}{2 g}+2 \xi_{b} \frac{u_{b}^{2}}{2 g}\right) \times \frac{G_{e}}{G_{N G}} \times 10^{-3}
$$

The flow velocity $u_{b}$ is calculated by mass flow rate and pipe diameter.

The flow in the tube is in the turbulent smooth zone in reality, so coefficient of path energy loss of the burner is determined by Equation (16), the flow in pipe and well as well. Therefore, the calculation equation of the coefficient of local energy loss of pipe and well will not be repeated below:

$$
\varsigma_{b}=\frac{0.3164}{\operatorname{Re}_{b}^{0.25}}
$$

A right angle loss and a valve loss are considered for coefficient of local energy loss of the burner. The coefficient of local energy loss of the limit value of a pipe section expansion is 1 and a valve opening of $50 \%$ is 1.8 . And the value of local loss coefficient is different for different components as show in Figure 1:

$$
\zeta_{b}=1+1.8
$$

(f) Energy out of the burner $Q_{b, t o, p}$ is solved by the conservation of energy equation. The calculation of the energy out of the pipe, well and soil is similar, so the equation will not be repeated below:

$$
Q_{b, t o, p}=Q_{a r, n e t}+Q_{a i r}-Q_{b, i n c}-Q_{b, l}-Q_{b, f}
$$

\subsubsection{Pipe}

Energy loss of flow $Q_{p, f}$ includes path energy loss only:

$$
Q_{p, f}=g \varsigma_{p} \frac{L_{p}}{d_{p, 2}} \frac{u_{p}^{2}}{2 g} \times \frac{G_{e}}{G_{N G}} \times 10^{-3}
$$

3.2.3. Well

(a) Energy of exhaust gas that flows from the outlet of the well to the environment:

$$
Q_{w, \text { out }}=\frac{1}{G_{N G}} \times G_{e} c_{p, e} t_{w, \text { out }}
$$

(b) Energy loss of flow $Q_{w, f}$ includes path energy loss and local energy loss:

$$
Q_{w, f}=g\left(\varsigma_{w} \frac{L_{w}}{d_{w, 1}} \frac{u_{w}^{2}}{2 g}+2 \zeta_{w} \frac{u_{w}^{2}}{2 g}\right) \times \frac{G_{e}}{G_{N G}} \times 10^{-3}
$$

Coefficient of local energy loss of the well:

$$
\xi_{w}=2.993+0.985
$$




\subsubsection{Soil}

(a) Energy loss of heat leakage in soil $Q_{s, l}$ includes the energy loss to the soil $Q_{s, l, s}$ and to the air $Q_{s, l, a}$. The leakage of heat from the soil to the air is conducted through an insulating layer covering the ground and the heat leakage to the surrounding soil is abstracted as heat transfer between two layers of cylindrical surfaces of a hollow cylinder:

$$
\left\{\begin{array}{c}
Q_{s, l}=Q_{s, l, s}+Q_{s, l, a} \\
Q_{s, l, s}=\frac{2 \pi \lambda_{s} L_{s}\left(t_{s}-t_{s, e}\right)}{\ln \frac{r_{s, e}}{r_{s}} \times \frac{1}{G_{N G}} \times 10^{-3}} \\
Q_{s, l, a}=\frac{\lambda_{i l} A_{i l}\left(t_{s}-t_{0}\right)}{\Delta i l} \times \frac{1}{G_{N G}} \times 10^{-3}
\end{array}\right.
$$

(b) Energy that the soil eventually use to heat up $Q_{s, a}$ :

$$
Q_{s, a}=Q_{s, i n}-Q_{s, l}
$$

\subsubsection{Energy Utilization Ratio}

Energy utilization ratio as performance indicators of the energy analysis were calculated by the energy that the soil ultimately uses and low calorific value of $1 \mathrm{~km}$ of NG:

$$
\eta_{e n}=\frac{Q_{s, a}}{Q_{a r, n e t}}
$$

\subsection{Exergy Analysis Model}

One kilogram of natural gas (NG) is the total exergy source of the system and the study about the exergy flow and the exergy loss is started with the exergy of one kilogram of natural gas (NG). The temperature used in modeling is shown in Table 1 or calculated in Appendix B (c).

\subsubsection{Burner}

(a) Reactant (natural gas) exergy $E_{r}$ is calculated as follows: [43]

$$
E_{r}=0.95 Q_{g a, v, a d}
$$

(b) $E_{\text {air }}$ is the exergy of air:

$$
E_{\text {air }}=0
$$

(c) Exergy loss of irreversible combustion in the burner calculated by reactant exergy $E_{r}$ and resultant exergy $E_{r s}[43]$ :

$$
\left\{\begin{array}{c}
E_{b, i r r}=E_{r}-E_{r s} \\
E_{r \mathrm{~s}}=\left(Q_{a r, n e t}-Q_{a r, n e t} \varepsilon\right)\left(1-\frac{T_{0}}{T_{b}-T_{0}} \ln \frac{T_{b}}{T_{0}}\right)
\end{array}\right.
$$

(d) Exergy loss of incomplete combustion is energy loss of incomplete combustion according to the definition of exergy:

$$
E_{b, i n c}=Q_{b, i n c}
$$

(e) Exergy loss of heat leakage is calculated by heat leakage energy and heat leakage temperature, and the calculation of burner, pipe, well and soil is similar. The tube surface temperature $T_{b, w, o}, T_{p, w, o}$, $T_{w, w, o}$ are regarded as leakage temperature calculated in Appendix B (c). The heat leakage temperature of soil is the soil temperature itself:

$$
\begin{aligned}
& E_{b, l}=Q_{b, l}\left(1-\frac{T_{0}}{T_{b, w, o}}\right) \\
& E_{p, l}=Q_{p, l}\left(1-\frac{T_{0}}{T_{p, w, o}}\right)
\end{aligned}
$$




$$
\begin{gathered}
E_{w, l}=Q_{w, l}\left(1-\frac{T_{0}}{T_{w, w, o}}\right) \\
E_{s, l}=Q_{s, l}\left(1-\frac{T_{0}}{T_{s}}\right)
\end{gathered}
$$

(f) Exergy loss of flow is energy loss of flow on account of the definition of exergy and the pipe as well as well is calculated in the same way as the burner:

$$
\begin{aligned}
E_{b, f} & =Q_{b, f} \\
E_{p, f} & =Q_{p . f} \\
E_{w, f} & =Q_{w, f}
\end{aligned}
$$

(g) Exergy out of the burner $E_{b, t o, p}$, is solved by the conservation of exergy equation. The calculation of the exergy out of the pipe, well and soil is similar, so the equation will not be repeated below:

$$
E_{b, t o, p}=E_{r}+E_{a i r}-E_{b, i r r}-E_{b, i n c}-E_{b, l}-E_{b, f}
$$

\subsubsection{Pipe}

This part of the calculation has been mentioned in Section 3.3.1.

\subsubsection{Well}

(a) Exergy loss due to heat transfer process $E_{x, Q}$ :

$$
\left\{\begin{array}{c}
E_{x, Q}=E_{x, Q_{H}}-E_{x, Q_{L}} \\
E_{x, Q_{H}}=\left(1-\frac{T_{0}}{T_{H}}\right) Q_{1} \\
E_{x, Q_{L}}=\left(1-\frac{T_{0}}{T_{L}}\right) Q_{2}
\end{array}\right.
$$

$E_{x, Q_{H}}$ is the calorific exergy of $Q_{1}$ at the temperature $\overline{T_{H}}$ and $E_{x, Q_{L}}$ is the calorific exergy of $Q_{2}$ at the temperature of $\overline{T_{L}} \cdot Q_{1}$ and $Q_{2}$ are considered equal calculated in Appendix $\mathrm{B}(\mathrm{a})$, while the amount of heat transferred in the heat transfer process varies in each stage. And the calculation of $\overline{T_{H}}$ and $\overline{T_{L}}$ are in Appendix B (d).

(b) Exergy loss of non-isothermal heat release is caused by temperature change of exhaust gas when flowing in the well:

$$
E_{x, Q_{1}}=T_{0} G_{e} c_{p, w} \ln \frac{T_{w, \text { in }}}{T_{w, \text { out }}}
$$

(c) Exergy of exhaust gas that flows from the outlet of the well to the environment is connected to the energy and temperature of exhaust gas:

$$
E_{w, \text { out }}=Q_{w, \text { out }}\left(1-\frac{T_{0}}{T_{w, \text { out }}-T_{0}} \ln \frac{T_{w, \text { out }}}{T_{0}}\right)
$$

\subsubsection{Soil}

(a).Exergy loss of non-isothermal heat absorption $E_{x, Q_{2}}$ is caused by temperature change of soil at three stages: In the first stage, the soil temperature rises from the initial temperature (environment temperature) $T_{0}$ to the boiling point of water $373 \mathrm{~K}$. The soil keeps the temperature of $373 \mathrm{~K}$ unchanged in the second stage. The third stage is to heat soil to increase the soil temperature to final temperature $T_{s}$ :

$$
\left\{\begin{array}{c}
E_{x, \mathrm{Q}_{2}, \mathrm{I}}=T_{0} m_{s} c_{p, s} \ln \frac{373}{T_{0}} \\
E_{x, \mathrm{Q}_{2}, \mathrm{II}}=0 \\
E_{x, \mathrm{Q}_{2}, \mathrm{III}}=T_{0} m_{p s} c_{p, p s} \ln \frac{T_{s}}{373}
\end{array}\right.
$$


(b) $E_{s, a}$ is the exergy that the soil eventually uses to heat up:

$$
E_{s, a}=E_{s, i n}-E_{x, Q_{2}}-E_{s, l}
$$

\subsubsection{Exergy Utilization Ratio}

Exergy utilization ratio as performance indicators of the exergy analysis were calculated by the exergy that the soil ultimately uses and exergy value of $1 \mathrm{~km}$ of NG:

$$
\eta_{e x}=\frac{E_{s, a}}{E r}
$$

\subsection{Process of Parameters Calculation in the Models}

As Figure 7 shows, the calculation process of parameters of energy analysis starts at the thermal requirements and ends at the energy. The calculations of excess air coefficient $\alpha$ and mass flow rates $G_{e}$ and $G_{N G}$ are given in Appendix B (a). These three parameters are used to solve the time needed of flowing $1 \mathrm{~km}$ natural gas (NG). The thermal flux has been modeled in Section 3.2. The calculation process of parameters of exergy analysis is similar to that of energy analysis.

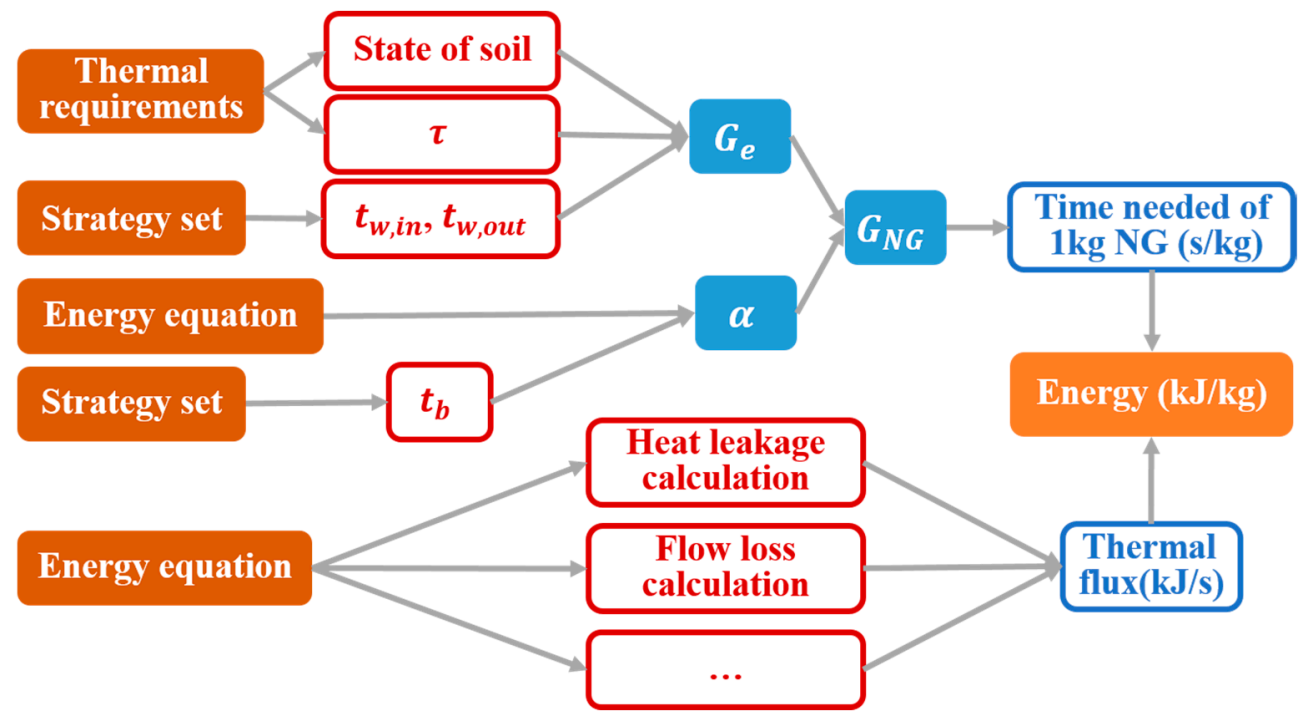

Figure 7. The flowchart of the parameters calculation in energy analysis.

\section{Results and Discussions}

In order to compare the effects of energy-saving strategies, the cases shown in Table 2 are designed. The traditional polluted-soil thermal remediation system, also named basic method (BM), is the fundamental case, Case BM. Case VCM applied energy-saving strategy for variable-condition mode with different exhaust gas temperatures at different stages. Energy-saving strategy for heat-returning mode is divided into 4 cases, among Case 3.1, Case 3.2 and Case 3.3, the difference is the rate of heat return. Case 3.4 combines variable-condition mode and heat-returning mode two energy-saving strategies. Energy-saving strategy for air-preheating mode is also divided into 4 cases, the difference is preheating ratio of air in Case 4.1, Case 4.2 and Case 4.3. As a comprehensive strategy for energy saving like Case 3.4, Case 4.4 combines variable-condition mode and air-preheating mode. 
Table 2. Cases set of basic method (BM) and energy-saving strategies.

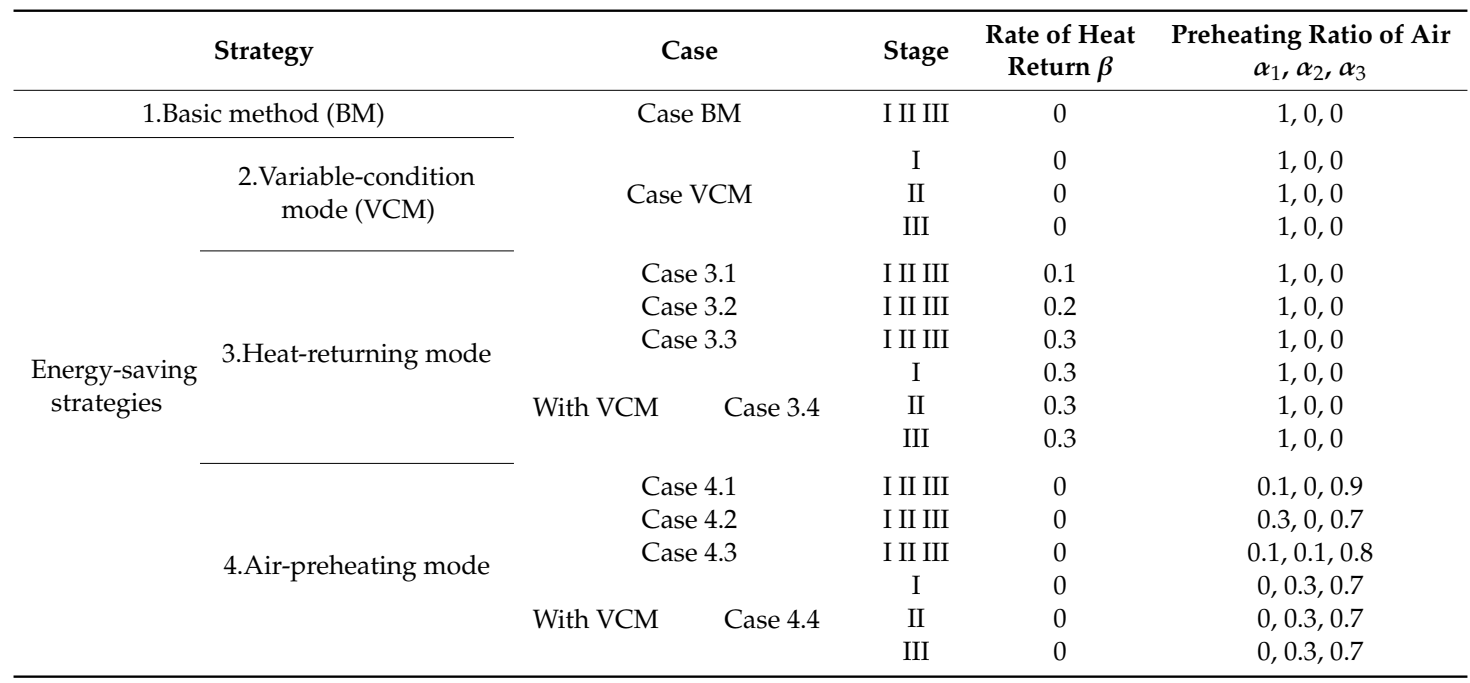

Next, the effect analysis of three energy-saving strategies is established in Sections 4.1-4.3, respectively. In Section 4.4, a comprehensive analysis of the energy-saving strategies will be presented.

\subsection{Energy Analysis and Exergy Anlysis of Variable-Condition Mode}

The most effective part of the variable-condition mode is that under the premise of the same heating demand and heating time, high amounts of natural gas (NG) can be saved. Table 3 lists the results of the mass flow rates of exhaust gas and NG, as well as the calculated excess air coefficient. The number of mass flow rates in the first stage of variable-condition mode (VCM) is $0.0299 \mathrm{~km}$ per second, much smaller than $0.1124 \mathrm{~km}$ per second of basis method (BM). The differences of mass flow rates and excess air coefficient of basic method (BM) and variable-condition mode (VCM) result from different temperatures of exhaust out of the well.

Table 3. Results of mass flow rates and excess air coefficient.

\begin{tabular}{ccccc}
\hline Strategy & Stage & $G_{\boldsymbol{e}}(\mathbf{k g} / \mathbf{s})$ & $G_{N G}(\mathbf{k g} / \mathbf{s})$ & $\alpha$ \\
\hline BM & I II III & 0.1124 & 0.0025 & 1.5510 \\
& I & 0.0299 & 0.000533 & 2.2470 \\
VCM & II & 0.1251 & 0.0024 & 1.9664 \\
& III & 0.0837 & 0.0022 & 1.1549 \\
\hline
\end{tabular}

Besides savings in the amount of natural gas (NG) usage, this paper is mainly focused on improving the energetic and exergetic performance of the polluted-soil thermal remediation system depending on energy-saving strategies. Energy utilization ratios and exergy utilization ratios, two of the performance indicators of the analysis, were calculated as the important results of the mathematical model. The energy utilization ratios and exergy utilization ratios of the BM and VCM varies from different stages as well as different modes of heat convection. Detailed results of energy utilization ratios and exergy utilization ratios are shown in Tables 4 and 5. Modes of heat convection affects energy performance and exergy performance obviously. It can be observed that the energy utilization ratio of forced convection each stage is $2.6 \%$ lower than that of free convection, and exergy utilization ratio is $0.9 \%$ lower as well. It is because that the forced convection causes more loss of thermal leakage. While the two exergy utilization ratios of VCM is identical. It is because that the thermal leakage of forced convection is bigger, but the temperature of the outer wall of burner is lower. The larger quantity of thermal leakage and the lower temperature of thermal leakage lead to the same exergy loss. 
Table 4. Energy utilization ratios of Case BM and Case VCM.

\begin{tabular}{ccccccc}
\hline \multirow{2}{*}{$\eta_{\text {en }}$} & \multicolumn{3}{c}{ Forced Convection } & \multicolumn{3}{c}{ Free Convection } \\
\cline { 2 - 7 } & I (\%) & II (\%) & III (\%) & I (\%) & II (\%) & III (\%) \\
\hline BM & 44.8 & 44.7 & 40.2 & 47.1 & 47 & 42.5 \\
VCM & 52.8 & 55.8 & 33.4 & 55.5 & 57.6 & 35.3 \\
\hline
\end{tabular}

Table 5. Exergy utilization ratios of Case BM and Case VCM.

\begin{tabular}{ccccccc}
\hline \multirow{2}{*}{$\eta_{\text {ex }}$} & \multicolumn{3}{c}{ Forced Convection } & \multicolumn{3}{c}{ Free Convection } \\
\cline { 2 - 7 } & I (\%) & II (\%) & III (\%) & I (\%) & II (\%) & III (\%) \\
\hline BM & 26 & 19.9 & 22.8 & 26.9 & 20.8 & 23.8 \\
VCM & 12.1 & 23.2 & 9.6 & 12.1 & 23.9 & 10.4 \\
\hline
\end{tabular}

Next, we assessed the energy and exergy efficiency using two curves more intuitively, as indicated in Figure 8. The utilization ratios' values of forced convection and free convection are different from the tables above, but the trend is the same, so the following analysis takes forced convection as an example. The energy utilization ratios of forced convection of the three stages are plotted in Figure $8 \mathrm{a}$, while exergy utilization ratios of forced convection of the three stages are plotted in Figure $8 \mathrm{~b}$. We combine the two curves of BM and VCM together to make our analysis simpler to understand.

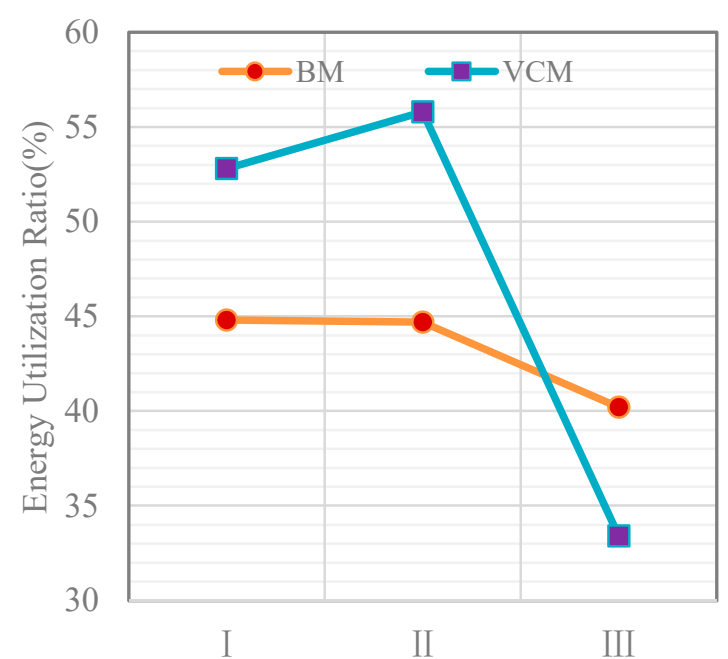

(a)

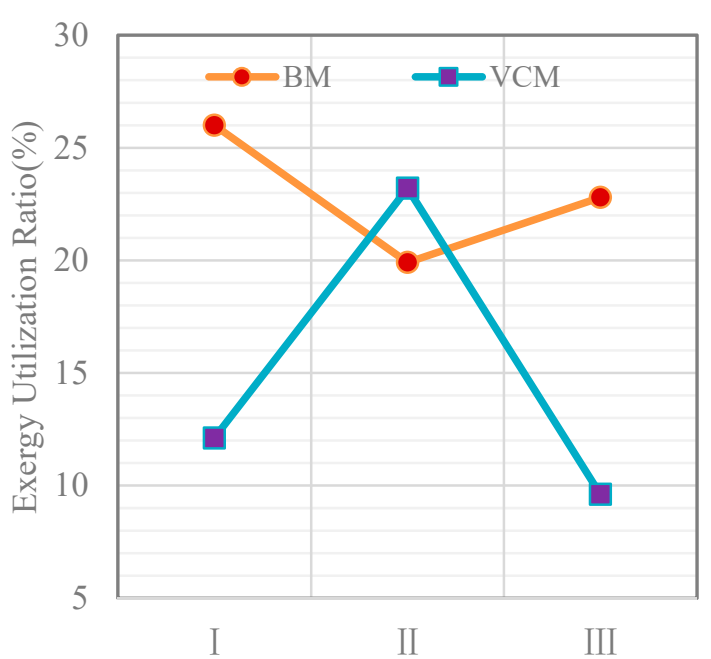

(b)

Figure 8. Energy utilization ratio and exergy utilization ratio comparisons of variable-condition mode (VCM) and basic method (BM): (a) Energy utilization ratio comparisons of variable-condition mode (VCM) and basic method (BM); (b) Exergy utilization ratio comparisons of variable-condition mode (VCM) and basic method (BM).

Figure 8a shows that energy utilization ratios of stage I in BM is not so very different from that of stage II. The lower temperature soil is heated by the higher temperature exhaust gas, which brings higher energy utilization ratios, but in stage III, the energy utilization ratio decreases significantly for maintaining the same temperature of exhaust gas, while the temperature of soil becomes higher and it becomes difficult to heat the soil. In VCM, stage II is the stage guaranteed the best performance of the whole heating process, as it maintains the highest values of the energy utilization ratio compared to other stages. In VCM, the energy utilization ratios of stage I and stage II are better than that of the same stage in BM, but stage III is worse because the temperature of exhaust gas in VCM is higher than that in BM bringing more heat loss due to exhaust gas and lower energy utilization ratio. 
Figure $8 \mathbf{b}$ shows that the exergy utilization ratios of stage II in BM is smaller than that in stage I and stage III because the thermal requirement in stage II is larger and the loss of irreversible combustion is larger as well. Comparing BM and VCM, we can find it that the exergy utilization ratios of VCM in stage I and stage III are lower for the reason of small mass flow rates. That is because the small mass flow rates resulting in the bigger flow time. Thermal flux calculated by formulas multiplied by time is the eventual thermal leakage energy. In stage II, when the mass flow rates of BM and VCM is similar, the exergy utilization ratios of VCM is larger.

The utilization ratio curves express intuitively the energy saving situation, but where the specific embodiment of energy savings is to be analyzed from the diagrams of energy flow and exergy flow. From the calculation results obtained, the data of energy loss and exergy loss of each component are used to draw energy flow diagrams and exergy flow diagrams of basic method (BM) and variable-condition mode (VCM) representing the flow of energy and exergy visually. The following analysis is concentrated on forced convection. The thickness of the arrows represents the size of the value. Regarding energy of $1 \mathrm{~km}$ natural gas (NG) as 100\%, the energy and exergy distribution fraction of various losses in each component of the system is presented in the Figure 9, so that comparing the losses of the two strategies is not difficult. The meanings of the parameters in all flow diagrams, including Figure 9, list in Table A2.

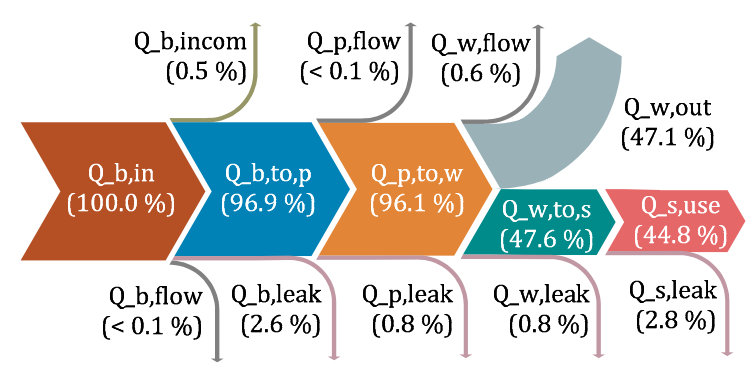

(a)

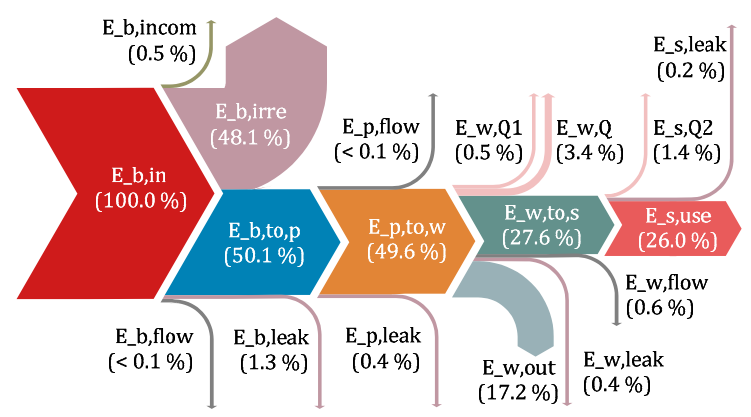

(c)

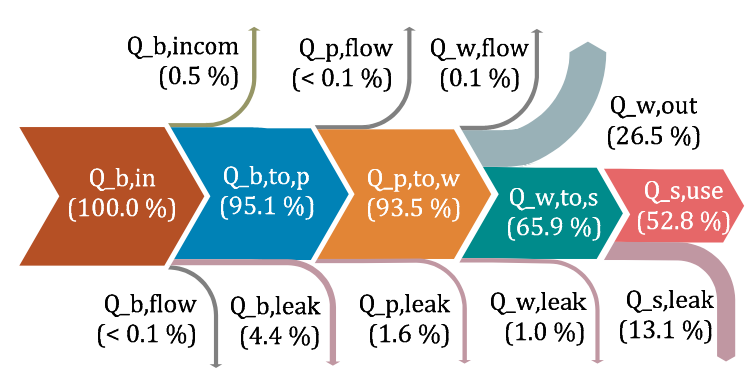

(b)

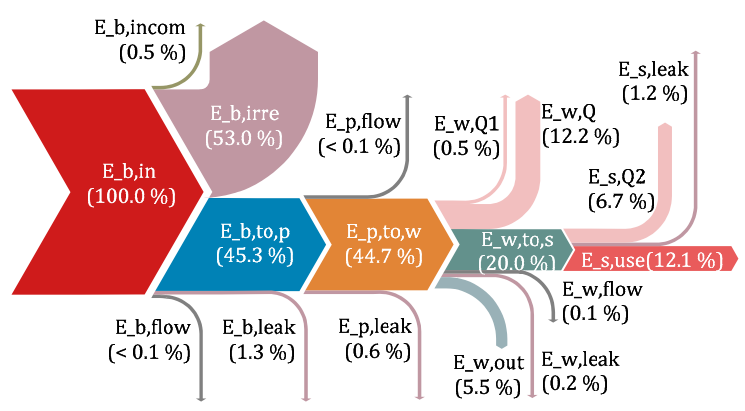

(d)

Figure 9. Flow diagrams of forced convection in stage I of of BM and VCM: (a) Energy flow diagram of forced convection in stage I of BM; (b) Energy flow diagram of forced convection in stage I of VCM; (c) Exergy flow diagram of forced convection in stage I of BM; (d) Exergy flow diagram of forced convection in stage I of VCM.

Comparing Figure 9a,b, it is observed that the energy in the exhaust gas is smaller in VCM compared with BM. The reason is that the temperature of exhaust gas in VCM is $200{ }^{\circ} \mathrm{C}$, lower than that in $\mathrm{BM}$ with the value of $450^{\circ} \mathrm{C}$ and this is the key to saving energy for VCM. It can be found by comparing Figure 9c,d that the exergy loss of irreversible combustion in BM is smaller than that in VCM. The reason is that exergy loss of irreversible combustion is associated with the adiabatic combustion temperature. The higher the adiabatic combustion temperature, the smaller the exergy loss of irreversible combustion. The adiabatic combustion temperature in VCM is lower in stage I, so that the exergy loss of irreversible combustion is bigger. Relative to energy, the energy saving strategy 
reduces more exergy loss of exhaust gas than energy loss. That is because the low temperature and the low energy of exhaust gas bring double effect of low exergy of exhaust gas. The increase of exergy loss impacted by mass flow rates is reflected in heat transfer process, non-isothermal heat release of exhaust gas and non-isothermal absorption of heat of soil. For example, when computing the exergy loss of non-isothermal heat release of exhaust gas of $1 \mathrm{~km}$ of natural gas (NG), the quantity of heat of non-isothermal heat release is an important factor. While the total quantity of heat of non-isothermal heat release in the first stage is settled, which is decided by the thermal requirements, in other words, the state of the soil. In the case of the same heat requirements and the same heating time, changing the temperature of exhaust gas from $450{ }^{\circ} \mathrm{C}$ to $200{ }^{\circ} \mathrm{C}$ in the first stage due to energy saving purpose results in the small amount of natural gas (NG). The total quantity of heat release maintained invariant, so that the exergy loss of one kilogram natural gas (NG) on average is bigger.

\subsection{Energy Analysis and Exergy Anlysis of Heat-Returning Mode}

The energy-saving strategy for heat-returning mode is returning the exhaust used to discharge to the atmospheric environment directly to the burner as the air in a certain proportion, Case 3.1 is with the rate of heat return of 0.1 , Case 3.2 with the rate of 0.2 and Case 3.3, the rate 0.3 . Using curves to assess the energy and exergy efficiency is the more intuitive way, as shown in Figure 10. And the specific distribution of energy and exergy loss as well as energy and exergy flow comparing with basic method (BM) are shown in Figure 11.

In Figure 10, it can be seen that all three case have higher utilization ratios than the basic method (BM), and the utilization ratios increase with increasing rate of heat return. The Case 3.3 with the largest rate of heat-returning has the best energy utilization ratio and exergy utilization ratio no matter what stage, which means the most significant energy-saving effect. However, the rate of heat return cannot always be increased without limit due to equipment and practical conditions. Compared with utilization ratios of Case 3.2 for Case 3.1, the Case 3.3 for Case 3.2 is more significant.

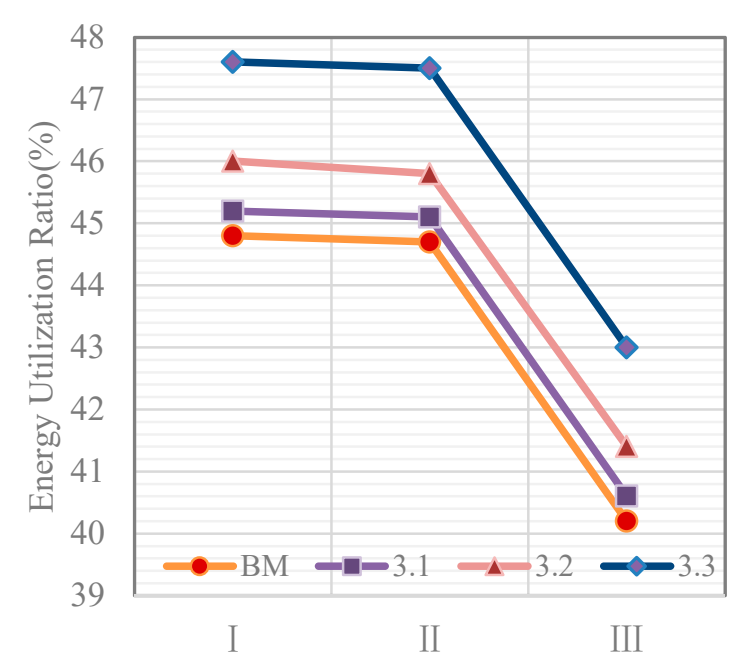

(a)

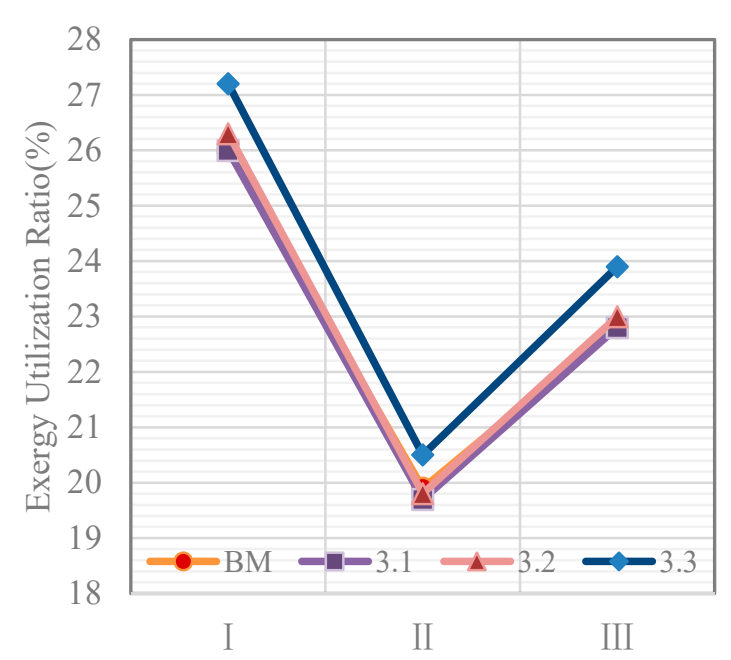

(b)

Figure 10. Energy utilization ratio and exergy utilization ratio comparisons of Case 3.1, Case 3.2 and Case 3.3 of heat-returning mode and basic method (BM): (a) Energy utilization ratio comparisons of Case 3.1, Case 3.2 and Case 3.3 of heat-returning mode and basic method (BM); (b) Exergy utilization ratio comparisons of Case 3.1, Case 3.2 and Case 3.3 of heat-returning mode and basic method (BM). 


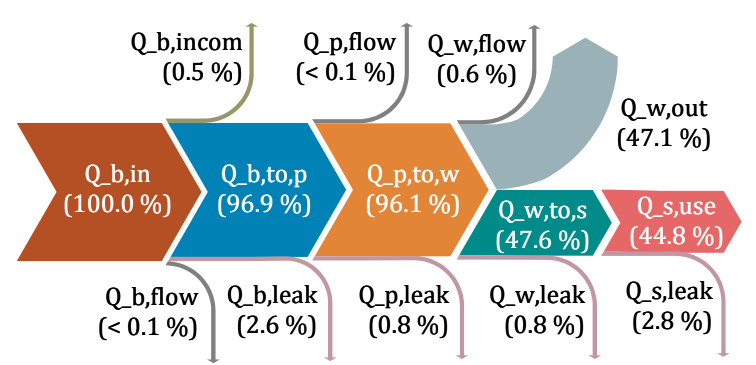

(a)

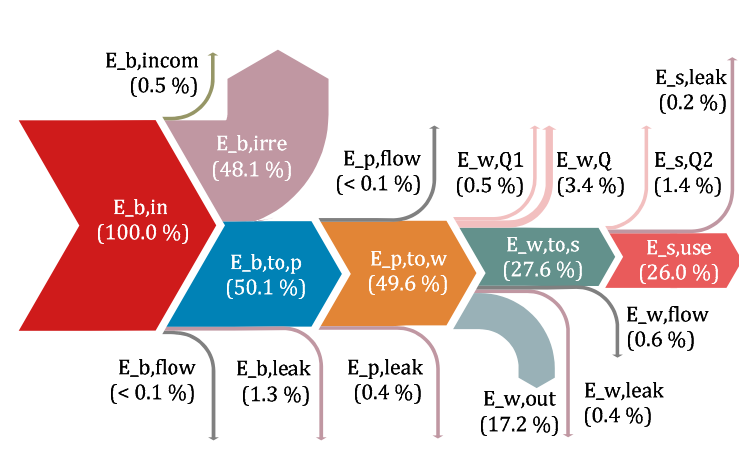

(c)

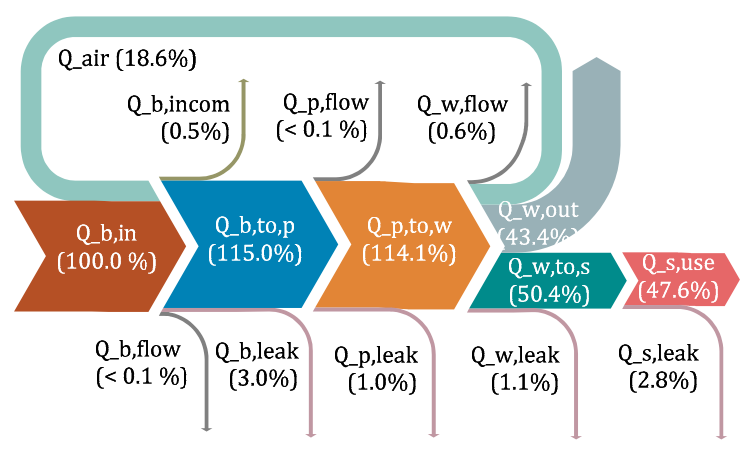

(b)

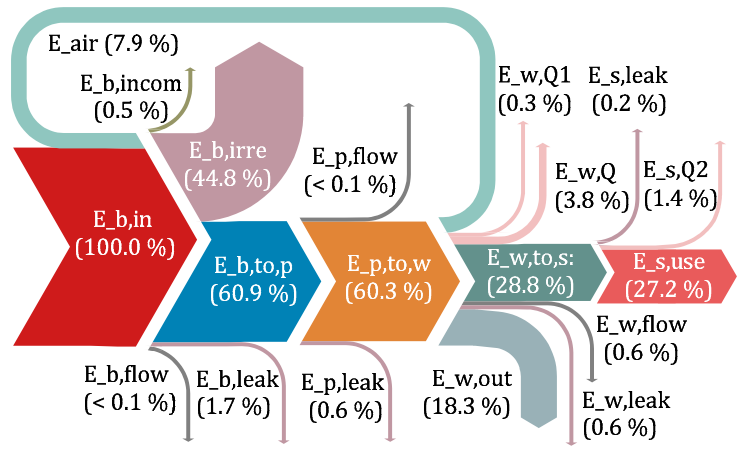

(d)

Figure 11. Flow diagrams of forced convection in stage I of BM and Case 3.3 of heat-returning mode: (a) Energy flow diagram of forced convection in stage I of BM; (b) Energy flow diagram of forced convection in stage I of Case 3.3 of heat-returning mode; (c) Exergy flow diagram of forced convection in stage I of BM; (d) Exergy flow diagram of forced convection in stage I of Case 3.3 of heat-returning mode.

The Case 3.3 with the best energy saving effect of the three cases of energy-saving strategy for heat-returning mode is selected to draw the energy flow diagram. From Figure 11a,b, there is a backflow of energy to the burner that is most obvious in Case 3.3, and it represents the heat-returning mode of exhaust. A Sankey diagram is a good way to show the flow of energy and the thickness of the arrows represents the size of the value in the diagram. With an initial energy of $1 \mathrm{~km}$ of natural gas, it is using the regenerative energy that to make more energy go into the system initially and it also results in more energy being used to heat the soil ultimately. While the energy loss of heat leakage of each component in Case 3.3 is bigger than that in BM for the reason of the higher temperature caused by more initial energy in the polluted-soil thermal remediation system. By comparing Figure 11c, $d$ that the exergy loss of irreversible combustion in Case 3.3 is smaller than that in BM as a result of higher adiabatic combustion temperature. And the analysis of exergy loss of heat leakage is the same as the energy analysis above, the higher temperature, the more energy loss, and the more exergy loss.

\subsection{Energy Analysis and Exergy Anlysis of Air-Preheating Mode}

The energy-saving strategy for air-preheating mode is setting preheaters to air-preheating mode using residual heat of the system. The cases in this section selected two places with high temperature and enough space to set the preheaters. In Case 4.1, the ratio of air through preheater 1 to be preheated is 0.1 , the ratio of air through preheater 2 to be preheated is 0 , and the ratio of air that does not pass through the preheater directly into the burner is 0.9 . In Case 4.2 , the ratio of air through preheater 1 to be preheated is 0.3 , the ratio of air through preheater 2 to be preheated is 0 , and the ratio of air that does not pass through the preheater directly into the burner is 0.7. In Case 4.3, the ratio of air through preheater 1 to be preheated is 0.1 , the ratio of air through preheater 2 to be preheated is 0.1 as well, and the ratio of air that does not pass through the preheater directly into the burner is 0.8 . Curves are 
used to assess the energy and exergy efficiency as shown in Figure 12. And the specific distribution of energy and exergy loss as well as energy and exergy flow comparing with basic method (BM) are shown in Figure 13.

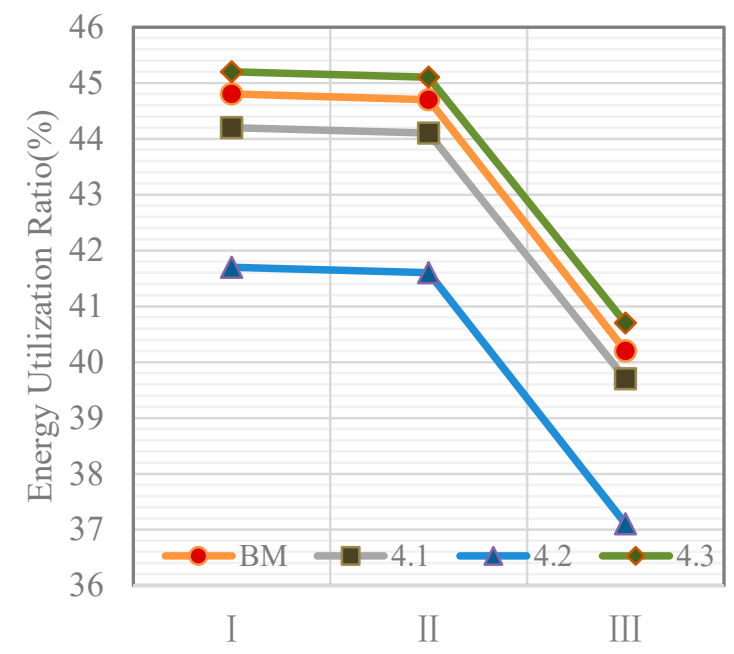

(a)

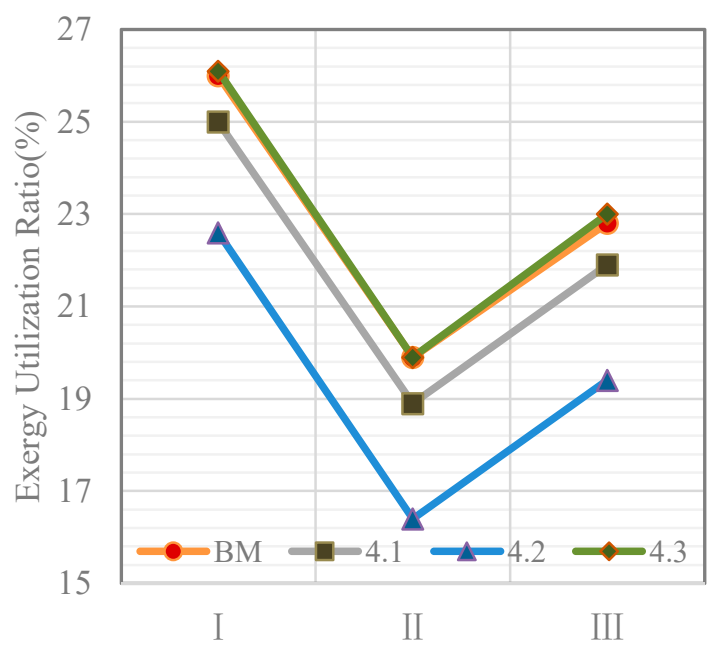

(b)

Figure 12. Energy utilization ratio and exergy utilization ratio comparisons of Case 4.1, Case 4.2 and Case 4.3 of heat-returning mode and basic method (BM): (a) Energy utilization ratio comparisons of Case 4.1, Case 4.2 and Case 4.3 of heat-returning mode and basic method (BM); (b) Exergy utilization ratio comparisons of Case 4.1, Case 4.2 and Case 4.3 of heat-returning mode and basic method (BM).

In Figure 12, it can be seen that the energy and exergy utilization ratio of Case 4.1 is smaller than that of $\mathrm{BM}$, and it is proved that the air preheating through the preheater 1 is not conducive to the improvement of utilization ratio and energy saving. The energy and exergy utilization ratio of Case 4.2 is even smaller than that of Case 4.1, that is to say, the effect of the preheater 1 wasting energy increases with the proportion of air passing through it. While the preheater 2 performs better, the energy utilization ratio of Case 4.3 is bigger than that of BM and the exergy utilization ratio is similar to that of BM under the bad interference of preheater 1. The underlying reason is that preheater 1 uses the energy to flow to the next component, while preheater 2 uses the waste heat to be drained into the air, so making full use of waste heat is the wonderful way to save energy, so in the Section 4.4 comprehensive energy-saving strategies, in Case 4.4, the ratio of air through preheater 1 to be preheated is 0 , the ratio of air through preheater 2 to be preheated is 0.3 , and the ratio of air that does not pass through the preheater directly into the burner is 0.7 .

Case 4.3 with the best energy saving effect of the three cases of energy-saving strategy for air-preheating mode is selected to draw the energy flow diagram. From Figure 13a,b, there are two backflows of energy to the burner in Case 4.3, and they represent preheated air with energy. Although the proportion of air through the preheater is not high, not much heat is brought back. The amount of energy used eventually increases a little with the increase in heat leakage accompanied by an increase in temperature. 


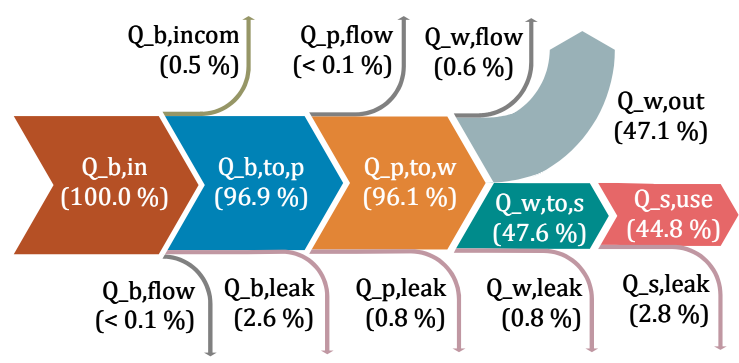

(a)

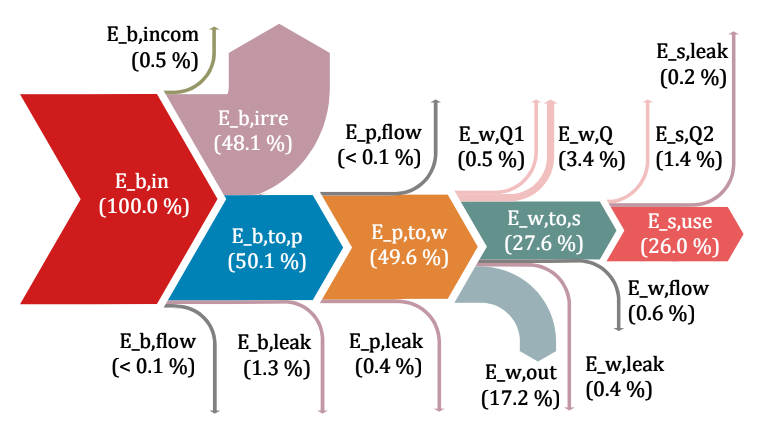

(c)

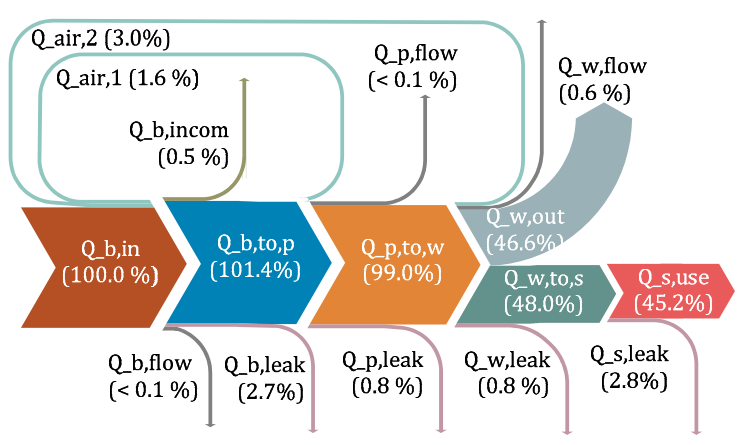

(b)

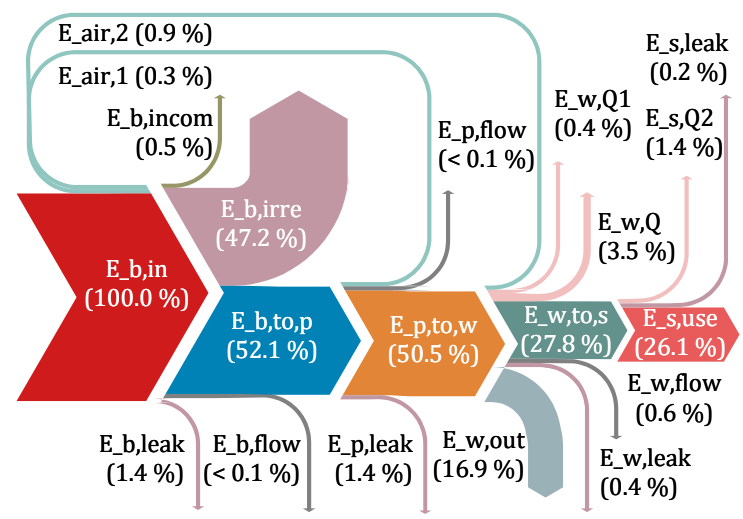

(d)

Figure 13. Flow diagrams of forced convection in stage I of BM and Case 4.3 of air-preheating mode: (a) Energy flow diagram of forced convection in stage I of BM; (b) Energy flow diagram of forced convection in stage I of Case 4.3 of air-preheating mode; (c) Exergy flow diagram of forced convection in stage I of BM; (d) Exergy flow diagram of forced convection in stage I of Case 4.3 of air-preheating mode.

\subsection{Energy Analysis and Exergy Anlysis of Comprehensive Energy-Saving Strategies}

The comprehensive energy-saving strategies are mainly to compare air-preheating mode combined with variable-condition mode (VCM) and heat-returning mode combined with variable-condition mode (VCM), that is Case 3.4 and Case 4.4. The rate of heat return in Case 3.4 is 0.3 and in Case 4.4 the ratio of air through preheater 2 to be preheated is 0.3 as well as the ratio of air that does not pass through the preheater directly into the burner is 0.7 . Because the variable-condition mode (VCM) were applied in both cases, so draw the energy utilization ratio curves for the three cases on one graph, Figure 14a, and draw the exergy utilization ratio curves on the other graph, Figure 14b, for easy comparison.

By comparing Figure 14a,b, in the three cases with variable-condition mode (VCM), the trend of energy utilization ratio and exergy utilization ratio curve is the same in the three stages. The second stage has the highest utilization ratio, then the first stage, then the third stage. The results in Figure 14a indicate that the Case 3.4 has the best energy utilization ratio in all three stages by combining the advantages of variable-condition mode (VCM) and heat-returning mode, that is to say, using two energy-saving strategies can bring the improvement of fuel saving and energy efficiency at the same time. The results of Case 4.4 have the same implications that Case 4.4 has better energy utilization ratio and exergy utilization ratio than Case VCM by combining the advantages of variable-condition mode (VCM) and air-preheating mode. If all three energy-saving strategies are combined, the structure of the system will become too complex and uncontrollable. Therefore, the combination of the two energy-saving strategies is recommendable. 


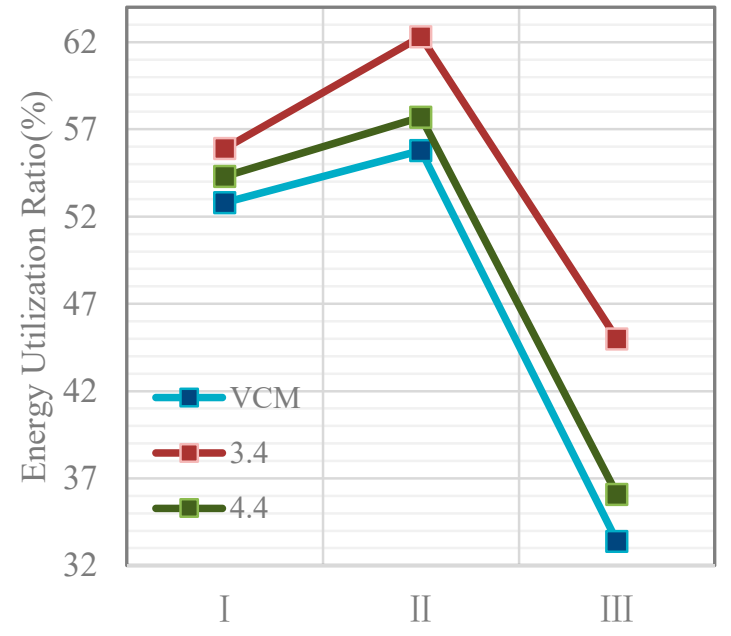

(a)

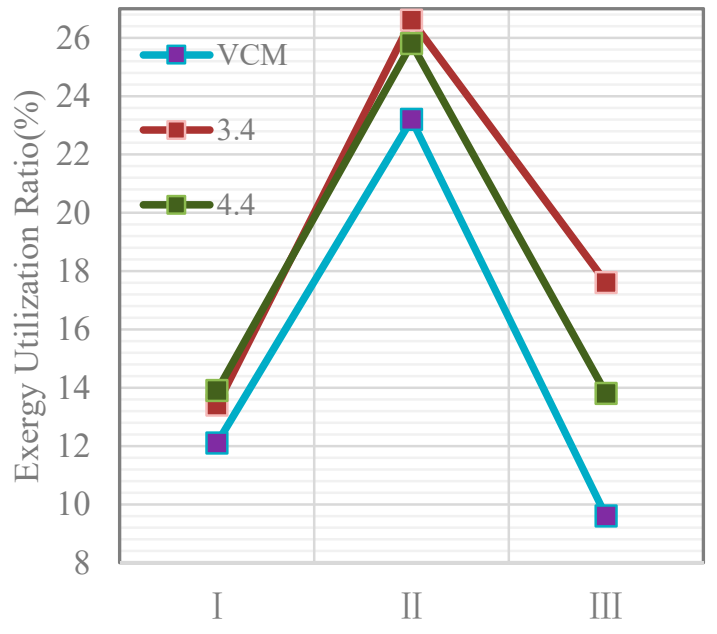

(b)

Figure 14. Energy utilization ratio and exergy utilization ratio comparisons of Case 3.4, Case 4.4 and variable-condition mode (VCM): (a) Energy utilization ratio comparisons of Case 3.4, Case 4.4 and variable-condition mode (VCM); (b) Exergy utilization ratio comparisons of Case 3.4, Case 4.4 and variable-condition mode (VCM).

\section{Conclusions}

This paper proposes three energy-saving strategies for a polluted-soil thermal remediation system - variable-condition mode (VCM), heat-returning mode and air-preheating mode-and their thermal performance and efficiency were discussed by energy analysis and exergy analysis. The mathematical models of a polluted-soil thermal remediation system including burner, pipe, well nd soil for energy and exergy analysis are built. The following main conclusions are reached:

- The most effective part of the energy-saving strategy for variable-condition mode (VCM) is that under the premise of the same heating demand and heating time, the usage amount of natural gas (NG) can be saved highly. The number of mass flow rates in the first stage of variable-condition mode (VCM) is $0.0299 \mathrm{~km}$ per second, much smaller than $0.1124 \mathrm{~km}$ per second of basis method (BM). It can be observed that the energy utilization ratio of forced convection each stage is $2.6 \%$ lower than that of free convection, and exergy utilization ratio is $0.9 \%$ lower as well. In VCM, the energy utilization ratio of stage I and stage II is better than that of the same stage in BM.

- All three energy-saving strategy cases for heat-returning mode have utilization ratios of $3 \%$ on average higher than the basic method (BM), and the utilization ratios increase with increasing rate of heat return. Case 3.3 with the largest rate of heat return has the best energy utilization ratio and exergy utilization ratio no matter what stage, which means the most significant energy-saving effect. That is because it is using the regenerative energy that to make more energy go into the system initially and it also results in more energy being used to heat the soil ultimately with an initial energy of $1 \mathrm{~km}$ of natural gas.

- In the analysis of energy-saving strategies for air-preheating mode, the air flowing through the preheater 1 to be preheated is not conducive to the improvement of utilization ratio and energy saving and the effect of the preheater 1 wasting energy increases with the proportion of air passing through it. While the preheater 2 performs better, the energy utilization ratio of Case 4.3 is bigger than that of BM and the exergy utilization ratio is similar to that of BM under the bad interference of preheater 1. The underlying reason is that preheater 1 uses the energy to flow to the next component, while preheater 2 uses the waste heat to be drained into the air. So making full use of waste heat is the wonderful way to save energy. 
- The comprehensive energy-saving strategies are mainly to compare air-preheating mode combined with variable-condition mode (VCM) and heat-returning mode combined with variable-condition mode (VCM). The results indicate that the Case 3.4 has the best energy utilization ratio in all three stages by combining the advantages of variable-condition mode (VCM) and heat-returning mode, and the results of Case 4.4 have the same implications. That is to say, combination of two energy-saving strategies can bring the improvement of fuel saving and energy efficiency at the same time and it is recommendable.

Research on methods and effects of energy-saving strategies is very beneficial for the full use of energy, for the reason of reduced natural gas consumption and higher energy utilization. Energy analysis and exergy analysis are also intuitive for the presentation of results. Further to say, resource problem can be solved better through the research of efficient use of energy.

Author Contributions: Conceptualization, Y.-Z.L.; methodology, T.-T.L.; software, T.-T.L.; validation, Y.-Z.L.; formal analysis, Z.-Z.Z.; investigation, E.-H.L.; writing—original draft preparation, T.-T.L.; writing-review and editing, T.L.; visualization, E.-H.L.; supervision, Y.-Z.L.; project administration, Y.-Z.L.

Funding: The project was funded by the Open Research Fund of Key Laboratory of Space Utilization, Chinese Academy of Sciences through grant no.LSU-JCJS-2017-1.

Conflicts of Interest: The authors declare no conflict of interest.

\section{Nomenclature}

\begin{tabular}{|c|c|c|c|}
\hline A & Area $\left(\mathrm{m}^{2}\right)$ & $\lambda$ & $\begin{array}{l}\text { Thermal conductivity } \\
\left(\mathrm{W} /\left(\mathrm{m}^{*} \mathrm{~K}\right)\right)\end{array}$ \\
\hline C & $\begin{array}{l}\text { Constant, depending on the Reynolds } \\
\text { number }\end{array}$ & $v$ & Kinematic viscosity $\left(\mathrm{m}^{2} / \mathrm{s}\right)$ \\
\hline$d$ & Diameter $(\mathrm{m})$ & $\xi$ & $\begin{array}{l}\text { Coefficient of local energy } \\
\text { loss }\end{array}$ \\
\hline E & Exergy (kJ/kg) & $\tau$ & Total time of the stage (days) \\
\hline$E_{r}$ & Reactant exergy $(\mathrm{kJ} / \mathrm{kg})$ & Subscript & \\
\hline$E_{r s}$ & Resultant exergy $(\mathrm{kJ} / \mathrm{kg})$ & air & Air \\
\hline$E_{x, Q}$ & $\begin{array}{l}\text { Exergy loss due to heat transfer } \\
\operatorname{process}(\mathrm{kJ} / \mathrm{kg})\end{array}$ & $b$ & Burner \\
\hline$E_{x, Q_{1}}$ & $\begin{array}{l}\text { Exergy loss due to non-isothermal heat } \\
\text { release }(\mathrm{kJ} / \mathrm{kg})\end{array}$ & $b, f$ & Flow loss in the burner \\
\hline$E_{x, Q_{2}}$ & $\begin{array}{l}\text { Exergy loss due to non-isothermal } \\
\text { absorption of heat }(\mathrm{kJ} / \mathrm{kg})\end{array}$ & $b, i n c$ & $\begin{array}{l}\text { Incomplete combustion in } \\
\text { the burner }\end{array}$ \\
\hline$E_{x, Q_{H}}$ & Heat exergy of $Q_{1}$ at $\overline{T_{H}}(\mathrm{~kJ} / \mathrm{kg})$ & $b, i r r$ & $\begin{array}{l}\text { Irreversible combustion in } \\
\text { the burner }\end{array}$ \\
\hline$E_{x, Q_{L}}$ & Heat exergy of $Q_{2}$ at $\overline{T_{L}}(\mathrm{~kJ} / \mathrm{kg})$ & $b, l$ & $\begin{array}{l}\text { Thermal leakage in the } \\
\text { burner }\end{array}$ \\
\hline$g$ & Gravitational acceleration $\left(\mathrm{m} / \mathrm{s}^{2}\right)$ & $b, t o, p$ & From burner to pipe \\
\hline G & Mass flow rate $(\mathrm{kg} / \mathrm{s})$ & $b, w, o$ & The outer wall of burner \\
\hline Gr & Grashof number & $b, 1$ & Interior burner \\
\hline$h$ & $\begin{array}{l}\text { Convective heat transfer coefficient } \\
\left(\mathrm{W} /\left(\mathrm{m}^{2} \cdot{ }^{\circ} \mathrm{C}\right)\right.\end{array}$ & $b, 2$ & External burner \\
\hline$l$ & characteristic length $(\mathrm{m})$ & $e$ & Exhaust \\
\hline$L$ & Length $(\mathrm{m})$ & $f, b$ & Fluid in the burner \\
\hline$m_{p s}$ & Quality of dry soil $(\mathrm{kg})$ & $f, p$ & Fluid in the pipe \\
\hline$m_{s}$ & Quality of soil $(\mathrm{kg})$ & $f, w$ & Fluid in the well \\
\hline$m_{w}$ & Quality of water in the soil $(\mathrm{kg})$ & il & Insulating layer \\
\hline$n$ & $\begin{array}{l}\text { Constant, depending on the Reynolds } \\
\text { number }\end{array}$ & $\mathrm{m}$ & At qualitative temperature \\
\hline $\mathrm{Nu}$ & Nusselt number & NG & Natural gas \\
\hline
\end{tabular}


Pr Prandtl number $\quad O$

$Q \quad$ Energy $(\mathrm{kJ} / \mathrm{kg})$

$Q_{a r, n e t} \quad$ Lower calorific value $(\mathrm{kJ} / \mathrm{kg})$

$Q_{g a, v, a d} \quad$ Higher calorific value $(\mathrm{kJ} / \mathrm{kg})$

$\operatorname{Re}$

$t$

$t_{b}$

$t_{0}$

$t_{s}$

T

$\overline{T_{H}}$

$\overline{T_{L}}$

$T_{0}$

$u$

Greek symbols

\section{$\alpha$}

$\alpha_{V}$

$\gamma$

$\Delta$

$\Delta t$

$\varepsilon$

$\eta_{e n}$

$\eta_{e x}$

$\varsigma$
Reynolds number

Temperature $\left({ }^{\circ} \mathrm{C}\right)$

Adiabatic combustion temperature $\left({ }^{\circ} \mathrm{C}\right)$

Ambient temperature $\left({ }^{\circ} \mathrm{C}\right)$

Soil temperature at the end of stage $\left({ }^{\circ} \mathrm{C}\right)$

Kelvin temperature (K)

Kelvin temperature of intermediate high temperature heat source (K)

Kelvin temperature of intermediate low temperature heat source $(\mathrm{K})$

Ambient kelvin temperature (K)

Velocity $(\mathrm{m} / \mathrm{s})$

Excess air coefficient

Cubic expansion coefficient

Latent heat of vaporization $(\mathrm{kJ} / \mathrm{kg})$

Thickness (m)

Temperature difference $\left({ }^{\circ} \mathrm{C}\right)$

Incomplete combustion coefficient

Energy utilization ratio

Exergy utilization ratio

Coefficient of path energy loss $p$

$p, f$

$p, i n$

$p, l$

$p, t o, w$

$p, w, o$

$s$

$s, a$

$s, e$

$s$, in

$s, l$

$s, l, a$

$s, l, s$

$w$

$w, f$

$w$, in

$w, l$

w, out

$w$, to, $s$

$w, w, o$

I

II

III
Extended well

Pipe

Flow loss in the pipe

Input of pipe

Thermal leakage in the pipe

From pipe to well

The outer wall of pipe

Soil

Absorbed by the soil

Unheated soil

Input of soil

Thermal leakage in the soil

Thermal leakage from

soil to soil

Thermal leakage from

soil to air

Well

Flow loss in the well

Input of well

Thermal leakage in the well

Output of well

Well to soil

The outer wall

of extended well

The first stage

The second stage

The third stage

Appendix A

Table A1. The Value of Physical Parameters.

\begin{tabular}{cc}
\hline Parameters & Value \\
\hline$c_{p, b}$ Specific heat of gas in burner & $1.2390 \mathrm{~kJ} /\left(\mathrm{kg}{ }^{*} \mathrm{~K}\right)$ \\
$c_{p, e}$ Specific heat of exhaust & $1.1850 \mathrm{~kJ} /\left(\mathrm{kg}^{*} \mathrm{~K}\right)$ \\
$c_{p, p s}$ Specific heat of pure soil & $0.84 \mathrm{~kJ} /\left(\mathrm{kg}^{*} \mathrm{~K}\right)$ \\
$c_{p, s}$ Specific heat of soil & $1.8480 \mathrm{~kJ} /\left(\mathrm{kg}^{*} \mathrm{~K}\right)$ \\
$c_{p, w}$ Specific heat of well & $4.2 \mathrm{~kJ} /\left(\mathrm{kg}^{*} \mathrm{~K}\right)$ \\
$d_{b, 1}$ Inner diameter of burner & $190 \mathrm{~mm}$ \\
$d_{b, 2}$ External diameter of burner & $200 \mathrm{~mm}$ \\
$d_{p, 1}$ Inner diameter of pipe & $89 \mathrm{~mm}$ \\
$d_{p, 2}$ External diameter of pipe & $97 \mathrm{~mm}$ \\
$d_{w, 1}$ Inner diameter of well & $89 \mathrm{~mm}$ \\
$d_{w, 2}$ External diameter of well & $97 \mathrm{~mm}$ \\
$g$ Acceleration of gravity & $9.8 \mathrm{~m} / \mathrm{s}^{2}$ \\
$L_{b}$ Length of burner & $0.5 \mathrm{~m}$ \\
$L_{0}$ Length of extension of the well & $0.3 \mathrm{~m}$ \\
$L_{p}$ Length of pipe & $0.2 \mathrm{~m}$ \\
$L_{w}$ Length of well & $13 \mathrm{~m}$ \\
$r_{s}$ Radius of heated soil & $1.5 \mathrm{~m}$ \\
$r_{s, e}$ Radius of unheated soil & $2 \mathrm{~m}$ \\
$\lambda_{b}$ Thermal conductivity of burner & $0.0311 \mathrm{~W} /(\mathrm{m} * \mathrm{~K})$ \\
$\lambda_{f}$ Thermal conductivity of fluid & Differs from parts \\
$\lambda_{p}$ Thermal conductivity of pipe & $0.0231 \mathrm{~W} /(\mathrm{m} * \mathrm{~K})$ \\
$\lambda_{s}$ Thermal conductivity of soil & $1.2 \mathrm{~W} /\left(\mathrm{m}^{*} \mathrm{~K}\right)$ \\
$\lambda_{w}$ Thermal conductivity of well & $0.0209 \mathrm{~W} /\left(\mathrm{m}^{*} \mathrm{~K}\right)$ \\
$v_{a i r}$ Kinematic viscosity of air & $30 \times 10^{-6} \mathrm{~m}{ }^{2} / \mathrm{s}$ \\
\hline &
\end{tabular}


Table A2. The meanings of the parameters in flow diagrams.

\begin{tabular}{|c|c|c|c|}
\hline Parameter & Meaning & Parameter & Meaning \\
\hline Q_air & Energy of air to burner & E_air & Exergy of air to burner \\
\hline$Q \quad b$, in & Input energy to burner of $1 \mathrm{~kg} \mathrm{NG}$ & $E \_b$, in & Input exergy to burner of $1 \mathrm{~kg} \mathrm{NG}$ \\
\hline$Q \_b, t o, p$ & Energy from burner to pipe & $E \_b, t_{0}, p$ & Exergy from burner to pipe \\
\hline Q_b, incomp & Energy loss of incomplete combustion & E_b, irre & Exergy loss of irreversible combustion \\
\hline$Q \_b$, flow & Energy loss of flow in burner & E_b,incomp & Exergy loss of incomplete combustion \\
\hline$Q \_b$, leak & Energy loss of heat leakage in burner & $E \_b$, flow & Exergy loss of flow in burner \\
\hline$\tilde{Q} p, t o, w$ & Energy from pipe to well & E_b, leak & Exergy loss of heat leakage in burner \\
\hline$Q \_p$, flow & Energy loss of flow in pipe & E_p,to,w & Exergy from pipe to well \\
\hline Q_p, leak & Energy loss of heat leakage in pipe & E_p, flow & Exergy loss of flow in pipe \\
\hline$Q \_w, o u t$ & Output energy of exhaust from well & E_p, leak & Exergy loss of heat leakage in pipe \\
\hline$\widetilde{Q} w$, to s & Energy from well to soil & E w,out & Output exergy of exhaust from well \\
\hline$\tilde{Q} \_w$, flow & Energy loss of flow in well & $E \_w$, to,s & Exergy from well to soil \\
\hline Q_w, leak & Energy loss of heat leakage in well & E_w, flow & Exergy loss of flow in well \\
\hline Q_s, use & Energy that soil use & E_w, leak & Exergy loss of heat leakage in well \\
\hline$Q \_s, l e a k$ & Energy loss of heat leakage in soil & $E \_w, Q 1$ & Exergy loss of non-isothermal heat release \\
\hline$E s, Q 2$ & Exergy loss of non-isothermal heat absorption & $E w, Q$ & Exergy loss of heat transfer \\
\hline E_s, leak & Exergy loss of heat leakage in soil & E_s, use & Exergy that soil use \\
\hline
\end{tabular}

\section{Appendix B Calculation of Intermediate Parameters}

(a) Excess Air Coefficient and Mass Flow Rates Calculation

Mass flow rate of exhaust gas is calculated by state of soil, duration of stages and the set temperature of the exhaust. However, in the basic method (BM) the required conditions for calculation in each stage are uniform, and in variable-condition mode (VCM) those are distinguishing because of different exhaust gas temperatures at different stages. Excess air coefficient is also different caused by varied adiabatic combustion temperature.

Thermal requirement is the quantity of heat in the heat transfer process from well to soil by exhaust gas. $Q_{\mathrm{I}}$ is the heat in the first stage, $Q_{\mathrm{II}}$ is in the second stage and $Q_{\mathrm{III}}$ is the third. $c_{p, s}$ is specific heat with the moisture content of 0.3 :

$$
\left\{\begin{aligned}
Q_{\mathrm{I}}= & m_{s} c_{p, s}\left(100-t_{0}\right) \\
& Q_{\mathrm{II}}=m_{w} \gamma \\
Q_{\mathrm{III}}= & m_{p s} c_{p, p s}\left(t_{s}-100\right)
\end{aligned}\right.
$$

Mass flow rate of exhaust gas in BM of the three stages are calculated uniformly, as follows. And in VCM the mass flow rates of exhaust gas of the three stages are calculated respectively using separate thermal requirement. Because the calculation method is same as that in BM, it will not be repeated here.

Mass flow rate of exhaust gas in BM:

$$
G_{e}=\frac{Q_{\mathrm{I}}+Q_{\mathrm{II}}+Q_{\mathrm{III}}}{\tau c_{p, e}\left(t_{w . \text { in }}-t_{w, \text { out }}\right)}=\frac{m_{s} c_{p, s}\left(100-t_{0}\right)+m_{w} \gamma+m_{p s} c_{p, p s}\left(t_{s}-100\right)}{\tau c_{p, e}\left(t_{w, \text { in }}-t_{w, \text { out }}\right)}
$$

In order to calculate the excess air coefficient $\alpha$, chemical equation: Equation (48) and energy equation: Equation (49) in burner is essential. The excess air coefficient $\alpha$ is the ratio of redundant air volume to the right air volume in a complete reaction:

$$
\begin{gathered}
\mathrm{CH}_{4}+2(1+\alpha) \mathrm{O}_{2}+\frac{2 \times 78}{21}(1+\alpha) \mathrm{N}_{2} \rightarrow \mathrm{CO}_{2}+2 \mathrm{H}_{2} \mathrm{O}+\frac{2 \times 78}{21}(1+\alpha) \mathrm{N}_{2}+2 \alpha \mathrm{O}_{2}+Q \\
G_{N G} q_{a r, \text { net }}(1-\varepsilon)+G_{N G} c_{p, N G} t_{N G}+G_{a i r} c_{p, a i r} t_{a i r}=G_{e} c_{p, b} t_{b}
\end{gathered}
$$

$c_{p, N G}$ is the specific heat of natural gas (NG) and $c_{p, a i r}$ is the specific heat of air. Because the temperature of natural gas (NG) and air are close to zero, the two parameters are not involved in the calculation.

Equation (50) is the excess air coefficient $\alpha$ :

$$
\alpha=\frac{\left(\frac{16 q_{a r, n e t}(1-\varepsilon)}{c_{p, b} t_{b}}-288.012\right)}{272.012}
$$

Mass flow rate of natural gas (NG) is corresponding to mass flow rate of exhaust gas one by one in each stage:

$$
G_{N G}=\frac{G_{e} \times 16}{272.012 \alpha+288.012}
$$


Convective heat transfer coefficient in the calculation of energy loss of heat leakage is divided to three categories:

(a) Convective heat transfer coefficient of forced convection in tube is as follows:

$$
\left\{\begin{array}{c}
\operatorname{Re}=\frac{u d}{v} \\
N u=0.023 \operatorname{Re}^{0.8} \operatorname{Pr}^{0.3} \\
h=\frac{\lambda_{f}}{d} N u
\end{array}\right.
$$

(b) Convective heat transfer coefficient of forced convection outside the tube is solved in Equation (53). The speed of the wind is 3 meters per second in the paper:

$$
\left\{\begin{array}{c}
\operatorname{Re}_{\text {air }}=\frac{u_{\text {air }} d}{v_{\text {air }}} \\
N u_{\text {air }}=C \operatorname{Re}_{\text {air }}^{n} \operatorname{Pr}_{\text {air }}^{1 / 3} \\
h_{\text {air }}=\frac{\lambda_{\text {air }}}{d} N u_{\text {air }}
\end{array}\right.
$$

(c) Equation (54) is the convective heat transfer coefficient of natural convection outside the tube:

$$
\left\{\begin{array}{c}
G r_{\text {air }}=\frac{g \alpha_{V} \Delta t l^{3}}{v_{\text {air }}^{2}} \\
N u_{\text {air }}=C\left(G r_{\text {air }} \operatorname{Pr}_{\text {air }}\right)_{m}^{n} \\
h_{\text {air }}=\frac{\lambda_{\text {air }}}{d} N u_{\text {air }}
\end{array}\right.
$$

(c) Tube Surface Temperature Calculation

$$
\begin{gathered}
\left\{\begin{aligned}
t_{b, w, o} & =\frac{Q_{b, l}}{L_{b} h_{b, 2} \pi d_{b, 2}}+t_{0} \\
T_{b, w, o} & =t_{b, w, o}+273.15
\end{aligned}\right. \\
\left\{\begin{aligned}
t_{p, w, o} & =\frac{Q_{p, l}}{L_{p} h_{p, 2} \pi d_{p, 2}}+t_{0} \\
T_{p, w, o} & =t_{p, w, o}+273.15
\end{aligned}\right. \\
\left\{\begin{aligned}
t_{w, w, o} & =\frac{Q_{w, l}}{L_{o} h_{w, 2} \pi d_{w, 2}}+t_{0} \\
T_{w, w, o} & =t_{w, w, o}+273.15
\end{aligned}\right.
\end{gathered}
$$

(d) Temperature of Intermediate Heat Source Calculation

In the actual heat transfer process, the temperature of the heat source will change as Figure A1 shows, so the temperature of intermediate heat source is essential to calculate. The logarithmic mean temperature difference is used to calculate the temperature of intermediate high temperature heat source $\overline{T_{H}}$, so as the temperature of intermediate low temperature heat source $\overline{T_{L}}$, and the $\overline{T_{L}}$ is different in each stage:

$$
\begin{gathered}
\overline{T_{H}}=\frac{T_{w, \text { in }}-T_{w, \text { out }}}{\ln \frac{T_{w, \text { in }}}{T_{w, \text { out }}}} \\
\left\{\begin{array}{c}
\overline{T_{L, I}}=\frac{373-T_{0}}{\ln \frac{373}{T_{0}}} \\
\overline{T_{L, \text { II }}}=373 \\
\overline{T_{L, \text { III }}}=\frac{T_{s}-373}{\ln \frac{T_{s}}{373}}
\end{array}\right.
\end{gathered}
$$




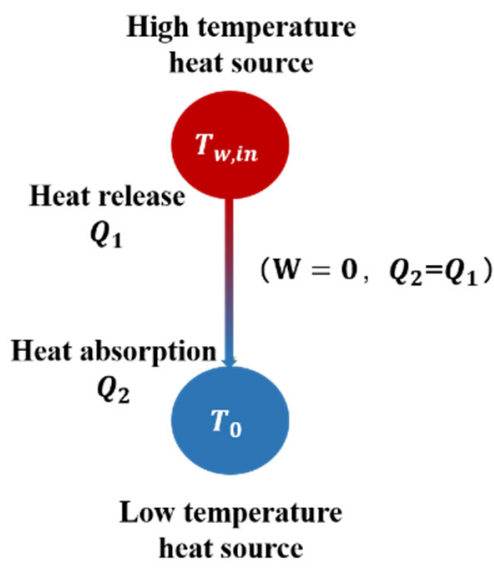

(a)

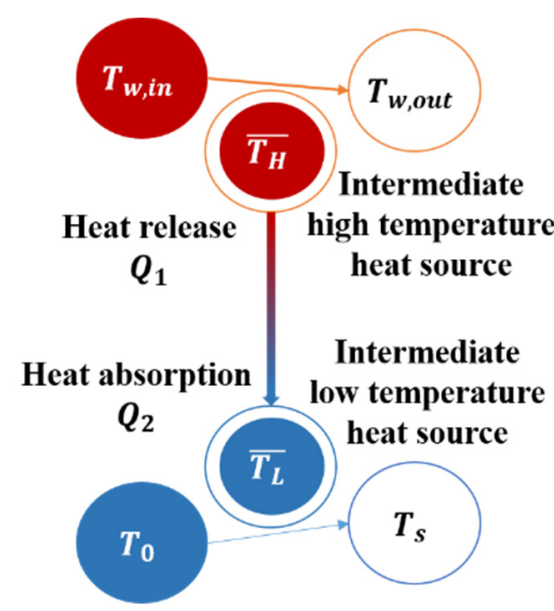

(b)

Figure A1. The heat transfer process: (a) The ideal heat transfer and (b) The actual heat transfer.

\section{References}

1. Yao, Z.T.; Li, J.H.; Xie, H.H.; Yu, C.H. Review on remediation technologies of soil contaminated by heavy metals. In Proceedings of the 7th International Conference on Waste Management and Technology, Beijing, China, 5-7 September 2012.

2. European Environment Agency. The European Environment e State and Outlook 2010: Soil; European Environment Agency: Copenhagen, Denmark, 2010; p. 44.

3. Liu, K.; Zhang, R.H.; Wang, S.J. Development and application of in situ thermal desorption for the remediation of contaminated sites. China Chlor. Alkali 2017, 12, 31-37.

4. Zhou, D.M.; Hao, X.Z.; Xue, Y. Advances in remediation technologies of contaminated soils. Ecol. Environ. Sci. 2004, 13, 234-242.

5. Cappuyns, V. Environmental impacts of soil remediation activities: Quantitative and qualitative tools applied on three case studies. J. Clean. Prod. 2013, 52, 145-154. [CrossRef]

6. Ministry of Environmental Protection of the People's Republic of China. Bulletin on Chinese Domestic Environmental Conditions of 2000 Year; Ministry of Environmental Protection of the People's Republic of China: Beijing, China, 2001.

7. Aresta, M.; DiBenedetto, A.; Fragale, C.; Giannoccaro, P.; Pastore, C.; Zammiello, D.; Ferragina, C. Thermal desorption of polychlorobiphenyls from contaminated soils and their hydrodechlorination using Pd- and Rh-supported catalysts. Chemosphere 2008, 70, 1052-1058. [CrossRef]

8. United States Environmental Protection Agency, Office of Solid Waste and Emergency Response. A Citizen's Guide to Thermal Desorption; 542-F-01-003; United States Environmental Protection Agency, Office of Solid Waste and Emergency Response: Washington, DC, USA, 2001; p. 2.

9. Luo, Y.M. Current Research and Development in Soil Remediation Technologies. Prog. Chem. 2009, 21, 558-565.

10. Araruna, J.T.J.; Portes, V.L.O.; Soares, A.P.L. Oil spills debris clean up by thermal desorption. J. Hazard. Mater. 2004, 110, 161-171. [CrossRef] [PubMed]

11. Yeung, A.T. Remediation technologies for contaminated sites. In Advances in Environmental Geotechnics; Zhejiang University Press: Hangzhou, China, 2010; pp. 328-369.

12. Feng, J.S.; Zhang, Q.C. A Review on the Study on Practice of Soil Remediation in situ. Ecol. Environ. Sci. 2014, 23, 1861-1867.

13. Fang, X.L.; Wang, Z.Z. Advances in in situ soil remediation technology. Agric. Technol. 2015, 18, $29-30$.

14. Lu, L.Q.; Ye, C.M. Advances in in situ remediation of heavy metal contaminated soils. Anhui Agric. Sci. Bull. 2017, 21, 69-70.

15. George, L.S.; Harold, J.V. Thermal conduction heating for in situ thermal desorption of soils. J. Hazard. Radioact. Waste Treat. Technol. Handb. 2001, 1-37.

16. Soesilo, J.A.; Stephanie, R.W. Site Remediation: Planning and Management; CRC Press: Boca Raton, FL, USA, 1997. 
17. Saadaoui, H.; Jourdain, S.; Falcinelli, U.; Haemers, J. In situ thermal treatment in urban polluted areas: Application of thermopile. In Proceedings of the 10th Consoil Conference, Milan, Italy, 3-6 June 2008; pp. 1-10.

18. Julia, E.V.; Kyriacos, Z.; Caroline, A.M.; Gabriel, S.; Pedro, J.J.A. Masiello Thermal Treatment of Hydrocarbon-Impacted Soils: A Review of Technology Innovation for Sustainable Remediation. J. Eng. 2016, 2, 426-437.

19. Rada, E.C.; Andreottola, G.; Istrate, I.A.; Viotti, P.; Conti, F.; Magaril, E.R. Remediation of Soil Polluted by Organic Compounds Through Chemical Oxidation and Phytoremediation Combined with DCT. Int. J. Environ. Res. Public Health 2019, 16, 3179. [CrossRef] [PubMed]

20. Sun, Y.; Guan, F.; Yang, W.; Wang, F. Removal of Chromium from a Contaminated Soil Using Oxalic Acid, Citric Acid, and Hydrochloric Acid: Dynamics, Mechanisms, and Concomitant Removal of Non-Targeted Metals. Int. J. Environ. Res. Public Health 2019, 16, 2771. [CrossRef] [PubMed]

21. Geiger, E.M.; Sarkar, D.; Datta, R. Evaluation of Copper-Contaminated Marginal Land for the Cultivation of Vetiver Grass (Chrysopogon zizanioides) as a Lignocellulosic Feedstock and its Impact on Downstream Bioethanol Production. Appl. Sci. 2019, 9, 2685. [CrossRef]

22. Tian, J.; Huo, Z.; Ma, F.; Gao, X.; Wu, Y. Application and Selection of Remediation Technology for OCPs-Contaminated Sites by Decision-Making Methods. Int. J. Environ. Res. Public Health 2019, 16, 1888. [CrossRef] [PubMed]

23. Elyamine, A.M.; Moussa, M.G.; Afzal, J.; Rana, M.S.; Imran, M.; Zhao, X.; Hu, C.X. Modified Rice Straw Enhanced Cadmium (II) Immobilization in Soil and Promoted the Degradation of Phenanthrene in Co-Contaminated Soil. Int. J. Mol. Sci. 2019, 20, 2189. [CrossRef]

24. Park, K.; Jung, W.; Park, J. Decontamination of Uranium-Contaminated Soil Sand Using Supercritical $\mathrm{CO}_{2}$ with a TBP- $\mathrm{HNO}_{3}$ Complex. Metals 2015, 5, 1788-1798. [CrossRef]

25. Navarro, A.; Cañadas, I.; Rodríguez, J. Thermal Treatment of Mercury Mine Wastes Using a Rotary Solar Kiln. Minerals 2014, 4, 37-51. [CrossRef]

26. Chonokhuu, S.; Batbold, C.; Chuluunpurev, B.; Battsengel, E.; Dorjsuren, B.; Byambaa, B. Contamination and Health Risk Assessment of Heavy Metals in the Soil of Major Cities in Mongolia. Int. J. Environ. Res. Public Health 2019, 16, 2552. [CrossRef]

27. Huang, X.; Luo, D.; Chen, X.; Wei, L.; Liu, Y.; Wu, Q.; Xiao, T.; Mai, X.; Liu, G.; Liu, L. Insights into Heavy Metals Leakage in Chelator-Induced Phytoextraction of $\mathrm{Pb}$ - and Tl-Contaminated Soil. Int. J. Environ. Res. Public Health 2019, 16, 1328. [CrossRef] [PubMed]

28. Lin, W.-C.; Lin, Y.-P.; Anthony, J.; Ding, T.-S. Avian Conservation Areas as a Proxy for Contaminated Soil Remediation. Int. J. Environ. Res. Public Health 2015, 12, 8312-8331. [CrossRef] [PubMed]

29. Christopher, D.E.; Daniel, Z.; Kimberly, E.B.; Benjamin, T.T.; Tilottama, G.; Dee, W.P.; Edward, H.E.; Mikhail, Z. A fifteen year record of global natural gas flaring derived from satellite data. Energies 2009, 2, 595-622.

30. Chen, J.; Wang, Y.-H.; Lang, X.-M.; Fan, S.-S. Energy-efficient methods for production methane from natural gas hydrates. J. Energy Chem. 2015, 24, 552-558. [CrossRef]

31. Heinz, S.; Steve, H.-D.; Thomas, W.; Arne, G.; Yiyong, C.; James, W.; David, N.; Tim, B.; Manfred, L.; Anne, O. Decoupling global environmental pressure and economic growth: Scenarios for energy use, materials use and carbon emissions. J. Clean. Prod. 2016, 132, 45-56.

32. Schmalensee, R.; Stoker, T.M.; Judson, R.A. World Carbon Dioxide Emissions: 1950-2050. Rev. Econ. Stat. 1998, 80, 15-27.

33. Yu, H.; Zhang, Z.Y.; Hua, L.; Wei, Y.M. China's farewell to coal: A forecast of coal consumption through 2020. Energy Policy 2015, 86, 444-455.

34. Chen, S.Y. Energy Consumption, $\mathrm{CO}_{2}$ Emission and Sustainable Development in Chinese Industry. Econ. Res. J. 2009, 4, 88-96.

35. Tang, D.; Dai, M. Energy-efficient Approach to Minimizing the Energy Consumption in an Extended Job-shop Scheduling Problem. Chin. J. Mech. Eng. 2015, 28, 1048-1055. [CrossRef]

36. Zou, C.; Zhao, Q.; Zhang, G.; Xiong, B. Energy revolution: From a fossil energy era to a new energy era. Nat. Gas Ind. B 2016, 3, 1-11. [CrossRef]

37. Carlos, G.M.; Alejandro, G.S.; Laurence, S.; Adisa, A. Life cycle environmental impacts of electricity from fossil fuels in Chile over a ten-year period. J. Clean. Prod. 2019, 232, 1499-1512. 
38. Wu, J.; Wang, J.; Wu, J.; Ma, C. Exergy and Exergoeconomic Analysis of a Combined Cooling, Heating, and Power System Based on Solar Thermal Biomass Gasification. Energies 2019, 12, 2418. [CrossRef]

39. Rangel-Hernandez, V.H.; Torres, C.; Zaleta-Aguilar, A.; Gomez-Martinez, M.A. The Exergy Costs of Electrical Power, Cooling, and Waste Heat from a Hybrid System Based on a Solid Oxide Fuel Cell and an Absorption Refrigeration System. Energies 2019, 12, 3476. [CrossRef]

40. Bobbo, S.; Fedele, L.; Curcio, M.; Bet, A.; De Carli, M.; Emmi, G.; Poletto, F.; Tarabotti, A.; Mendrinos, D.; Mezzasalma, G.; et al. Energetic and Exergetic Analysis of Low Global Warming Potential Refrigerants as Substitutes for R410A in Ground Source Heat Pumps. Energies 2019, 12, 3538. [CrossRef]

41. Valencia, G.; Fontalvo, A.; Cárdenas, Y.; Duarte, J.; Isaza, C. Energy and Exergy Analysis of Different Exhaust Waste Heat Recovery Systems for Natural Gas Engine Based on ORC. Energies 2019, 12, 2378. [CrossRef]

42. Lin, Z.H.; Xu, T.M. Utility Boiler Manual; Chemical Industry Press: Beijing, China, 1999.

43. Exergy efficiency testing technical procedures for industrial boilers. DB21-T 2567-2016.

(C) 2019 by the authors. Licensee MDPI, Basel, Switzerland. This article is an open access article distributed under the terms and conditions of the Creative Commons Attribution (CC BY) license (http://creativecommons.org/licenses/by/4.0/). 